\title{
Transfected Rat High-Molecular-Weight Neurofilament (NF-H) Coassembles with Vimentin in a Predominantly Nonphosphorylated Form
}

\author{
Steven S. M. Chin ${ }^{1,2}$ and Ronald K. H. Liem ${ }^{1}$ \\ 'Departments of Pathology and of Anatomy and Cell Biology, College of Physicians and Surgeons of Columbia \\ University, New York, New York 10032 and '2Department of Pharmacology, New York University Medical Center, \\ New York, New York 10016
}

\begin{abstract}
A fully encoding cDNA for the high-molecular-weight rat neurofilament protein (NF-H) has been isolated from a $\lambda g t 11$ library, sequenced and subcloned into eukaryotic expression vectors. Sequence analysis shows that rat NF-H has an overall homology of 72 and $88 \%$ with human and mouse NF$H$, respectively. The head and rod domains are almost entirely identical, and the divergences are due to differences in the long $\mathrm{C}$-terminal extensions of the molecule. The consensus phosphorylation sequence for neurofilaments LysSer-Pro (KSP) is present 52 times. The predicted molecular mass of the protein is $115 \mathrm{kDa}, 42 \%$ lower than that observed by SDS-PAGE.

Upon transfection into vimentin-containing fibroblasts, such as $L$ tk $^{-}$, L929, and 3 T6 cells, NF-H is seen distributed with vimentin by light and electron microscopic examinations indicating that copolymers of NF-H and vimentin are formed in these cells. Only a negligible proportion of the cells is positive when stained with a number of antibodies directed against phosphorylated NF-H epitopes. This is in contrast with the middle molecular weight NF protein (NF-M) transfected into $L t^{-}$and $L 929$ cells, which can readily be detected by antibodies against phosphorylated neurofilament epitopes. The mobilities of the transfected protein on 1- and 2-dimensional gels confirm that NF-H is predominantly in a nonphosphorylated form. These results indicate that phosphorylation of NF-H, but not NF-M, on the KSP sequence is due to protein kinases, which are not present in fibroblasts and are presumably NF-H specific. The stable NF-H-expressing cell lines can therefore be used to study these putative neurofilament kinases in vitro and in vivo.
\end{abstract}

Most large mammalian neurons exhibit an intermediate filament (IF) network mainly composed of 3 proteins referred to as the neurofilament (NF) triplet. The constituents of this triplet are known as NF-L, NF-M, and NF-H for the low-, middle-, and high-molecular-mass neurofilament proteins, respectively. These IF proteins are classified as type IV IF proteins on the

This study was supported by Grants NS15182 (Jacob Javits Neuroscience Award) and EYO3849. S.S.M.C. is supported by an NIH Medical Scientist Training Program grant at the New York University School of Medicine. We thank Mr. Ray Manson for photographic assistance.

Correspondence should be addressed to Ronald K. H. Liem, Ph.D., Department of Pathology, Columbia University College of Physicians and Surgeons, 630 West 168th St., New York, NY 10032.

Copyright (C) 1990 Society for Neuroscience $0270-6474 / 90 / 113714-13 \$ 03.00 / 0$
}

basis of their neuron-specific expression, unique amino acid sequence features, and placement of introns within the genome. NF-L has been shown to assemble in vitro into homopolymeric, 10-nm filamentous structures much like those seen with the type III IFs (vimentin, desmin, glial fibrillary acidic protein, and peripherin; Geisler and Weber, 1981 ; Liem and Hutchison, 1982). In contrast, NF-M assembles into a polymorphic variant of true IF structure, while NF-H assembles into short, stubby, filamentlike structures (Liem and Hutchison, 1982; Gardner et al., 1984). Such assembly studies and antibody decoration experiments (Willard and Simon, 1981; Hirokawa et al., 1984) have established that NF-L comprises most of the backbone of NFs. NF-M and NF-H coassemble with NF-L into the IF backbone and appear to contribute to the peripheral cross-bridges unique to NFs.

Like all IF proteins, the NF triplet proteins conform to a tripartite structure consisting of a highly conserved central segmented $\alpha$-helical rod domain of $\sim 310$ amino acid residues, flanked by a variable amino-terminal "head" domain and a highly variable carboxyl-terminal "tail" domain (Steinert and Roop, 1988). As a result of their extensive carboxyl-terminal tail domains, NF-M and NF-H are 2 of the largest IF proteins known. Additionally, they are among the most highly phosphorylated proteins known, and it has been shown that the major phosphorylation sites are located within the tail domain and consist of the consensus tripeptide sequence (Lys-Ser-Pro (KSP; Geisler et al., 1987; Lee et al., 1988). It has also been demonstrated that the observed molecular masses of NF-M and NF-H in SDS-PAGE are anomalous and are partially due to their phosphorylation state (Carden et al., 1985; Lewis and Nixon, 1988).

Although much is known about the biochemistry and primary sequence of many of the IF proteins, their exact cytoskeletal functions are still largely unknown. The situation is the same with the NF proteins. Forced expression of the NF proteins in cells that normally do not express these polypeptides has been initiated in an attempt to define possible functions for these structural elements. Monteiro and Cleveland (1989) and our laboratory (Chin and Liem, 1989) have recently shown that NF-L and NF-M coassemble with the endogenous vimentin cytoskelcton when transfected into cultured fibroblasts. These results demonstrated that NF-L and NF-M expression did not seem to perturb the normal functions of the transfected cells, and that these proteins behaved very much like a type III IF in vivo. In order to study the expression, assembly properties, and 
phosphorylation of NF-H in vivo, we have used DNA transfection procedures to introduce a fully encoding rat NF-H cDNA into cultured cell lines.

\section{Materials and Methods}

Antibodies. Mouse monoclonal BMB NF68 anti-neurofilament $68-\mathrm{kDa}$ (clone NR 4), mouse monoclonal BMB NF160 anti-neurofilament 160$\mathrm{kDa}$ (clone NN 18), and mouse monoclonal BMB NF200 anti-neurofilament $200-\mathrm{kDa}$ (clone NE 14) antibodies (mAbs) were purchased from Boehringer Mannheim Biochemicals (BMB; Indianapolis, IN). Mouse monoclonal anti-nonphosphorylated neurofilaments, SMI 32, and mouse monoclonal anti-phosphorylated neurofilaments, SMI 31, were purchased from Sternberger-Myer Immunocytochemicals Inc. (Jarrettsville, MD). Mouse monoclonal anti-NF-H (clone NF2) and rabbit polyclonal anti-tubulin antibodies were prepared in our laboratory and were previously described (Liem et al., 1978, 1985). A rabbit polyclonal antivimentin was a generous gift from Dr. Eugenia Wang (Lady Davis Institute for Medical Research, Montreal). Goat anti-rabbit IgG and goat anti-mouse IgG secondary antibodies conjugated with fluorescein isothiocyanate (FITC) were purchased from Antibodies, Inc. (Davis, CA). Tetramethylrhodamine isothiocyanate- (TRITC) labeled goat antirabbit IgG and goat anti-mouse IgG were from Cappel Laboratories (Cochranville, PA). Goat anti-mouse IgG labeled with $15-\mathrm{nm}$ colloidal gold and goat anti-rabbit IgG labeled with $5-\mathrm{nm}$ colloidal gold were purchased from Janssen Life Sciences Products (Olen, Belgium). Horseradish peroxidase-conjugated goat anti-mouse $\mathrm{IgG}$ was purchased from HyClone Laboratories, Inc. (Logan, UT).

Screening of rat-brain cDNA library. Isolation and characterization of fully encoding rat NF-M and NF-L cDNA clones have previously been described (Napolitano et al., 1987; Chin and Liem, 1989). Dr. Ivan Lieberburg (Athena Neurosciences, CA) generously supplied a 2.1$\mathrm{kb}$ cDNA clone encoding the carboxyl-terminal portion of the rat NF-H polypeptide (Lieberburg et al., 1989). We used this clone to rescreen the amplified $\lambda$ gt 11 cDNA expression library (from Dr. D. Colman, Columbia University, NY) prepared from 21-d-old rat brain RNA from which we had previously isolated fully encoding NF-M and NF-L cDNAs (Napolitano et al., 1987; Chin and Liem, 1989). The 2.1-kb cDNA insert was purified, labeled with ${ }^{32} \mathrm{P}$-dCTP [New England Nuclear (NEN), Boston, MA] by nick translation (Rigby et al., 1977), hybridized to nitrocellulose replicas containing recombinant phage, washed to a final stringency of $0.2 \times \mathrm{SSC}$ at $68^{\circ} \mathrm{C}$, and exposed to $\mathrm{x}$-ray film. Positive plaques were amplified, and their cDNA inserts were sized by Southern blot analysis. The largest cDNA clone was subcloned into pGEM-3 (Promega, Madison, WI) and into the bacteriophage vectors M13mp18 and M13mp19 (New England BioLabs, Inc., Beverly, MA).

DNA sequencing. DNA sequencing was performed according to the dideoxy chain termination protocol as described by Sanger et al. (1980). Deoxyadenosine $5^{\prime}-\left(\alpha^{-3} \mathrm{~S}\right.$-thio)triphosphate (NEN) was used as the label incorporated in the dideoxynucleotide sequencing reactions (Biggin et al., 1983). The rapid deletion system described by Dale et al. (1985) was used to generate the required overlapping subclones for sequencing. Synthetic oligonucleotide primers were used to sequence through regions not covered by the deletion clones. Klenow fragment of $E$. coli DNA polymerase I, T4 DNA polymerase, terminal deoxyribonucleotidyl transferase, and subcloning primers RD22-mer and RD29-mer were purchased from International Biotechnologies, Inc. (IBI; New Haven, CT).

Sequence analysis. Nucleotide and peptide sequences were analyzed using the DNA/Protein Sequence Analysis System written by James M. Pustell and IBI (Pustell and Kafatos, 1984).

In vitro transcription/translation. Transcription experiments were performed in the presence of either the Sp6 or T7 RNA polymerase for $1 \mathrm{hr}$ at $40^{\circ} \mathrm{C}$, following the protocol recommended for the Riboprobe Gemini System (Promega; Melton et al., 1984). The resulting in vitro transcribed mRNA was translated in a rabbit reticulocyte lysate system (NEN) containing Tran- ${ }^{3}$ S-label (ICN Biochemicals, Inc., Irvine, CA) according to the procedure specified by the manufacturer. The ${ }^{35} \mathrm{~S}-\mathrm{la}$ beled translation products were separated on SDS-PAGE and processed for fluorography (Laskey and Mills, 1975; Chamberlain, 1979). The translation products were also separated by 2-dimensional nonequilibrium pH gel electrophoresis (NEPHGE) in order to determine isnelectric point values. These gels were performed essentially as described by O'Farrell (1975) and Butler and Shelanski (1986).
Construction of $p R S V i-N F H$ and $p S V 2 i-N F H$ expression plasmids. The rat NF-H expression vectors were constructed in the same manner as previously described for the rat NF-L and NF-M expression plasmids (Chin and Liem, 1989). The NF-H cDNA insert was isolated by agarose gel electrophoresis and glass powder purification (Vogelstein and Gillespie, 1979). The purified insert was blunt ended by filling in with the large Klenow fragment of $E$. coli DNA polymerase I. Freshly phosphorylated (with T4 polynucleotide kinase) HindIII linkers (BMB) were ligated onto the ends of these DNA inserts using high-concentrate T4 DNA ligase (BMB). The linkered inserts were digested with excess HindIII for $1 \mathrm{hr}$ at $37^{\circ} \mathrm{C}$ and subjected to agarose gel electrophoresis followed by glass powder purification. These modified $\mathrm{cDNAs}$ were ligated into pGEM (Promega) or pTZ1 8U (United States Biochemical Corp., Cleveland, $\mathrm{OH})$ vectors that had been digested with HindIII and dephosphorylated with bacterial alkaline phosphatase (BAP). After the intermediate producer plasmids were constructed and isolated, purified insert with HindIII ends was ligated into expression vectors pSV2i-HindIII and pRSVi-HindIII (Forman et al., 1988) that had been linearized with HindIII and treated with BAP. After an overnight ligation at $14^{\circ} \mathrm{C}$, the reaction mixes were used to transform competent $E$. coli $\mathrm{HB} 101$ cells. Ampicillin-resistant colonies were picked, and miniplasmid preparations were analyzed by restriction digestion. Clones containing the NF-H cDNA insert in either the sense or antisense orientation relative to the viral promoters were recovered and amplified, and the plasmid DNA was isolated and purified through $\mathrm{CsCl}$ gradient centrifugation.

Cell culture. Mouse $\mathrm{L} \mathrm{tk}^{-}$and L929, Cos1 and Cos7, and Swiss 3T6 cell lines were maintained in Dulbecco's modified Eagles medium (DME) containing 10\% newborn calf serum (NBCS), $200 \mathrm{U} / \mathrm{ml}$ penicillin, and $200 \mu \mathrm{g} / \mathrm{ml}$ streptomycin sulfate (Gibco Laboratories, Grand Island, NY). The stably transfected cell line LS-NFM 15-1 (Chin and Liem, 1989) was maintained in the same culture medium containing $400 \mu \mathrm{g} / \mathrm{ml} \mathrm{G418}$ (Geneticin, Gibco Laboratories). All cells were cultured at $37^{\circ} \mathrm{C}$ under $7 \% \mathrm{CO}_{2}$ and $80 \%$ humidity. Cells designated for immunofluorescent staining were grown on untreated, sterile glass coverslips. For colchicine treatment, transfected cells were treated with $5 \mu \mathrm{M} / \mathrm{ml}$ colchicine (Sigma) in complete DME culture media for 2-6 hr under normal culture conditions.

Transient transfections. The following modified transient transfection protocol of Lopata et al. (1984) was used. Cells were plated 1-2 d beforehand at approximately $1 \times 10^{6}$ cells per $100-\mathrm{mm}$ culture dish in regular culture medium. On the day of transfection, supercoiled plasmid DNA ( $10 \mu \mathrm{g}$ for most experiments) was diluted into $0.5 \mathrm{ml}$ Tris-buffered saline [TBS; $25 \mathrm{~mm}$ Tris, $150 \mathrm{~mm} \mathrm{NaCl}, 5 \mathrm{~mm} \mathrm{KCl} \mathrm{(pH,} \mathrm{7.4)],} \mathrm{and} 5$ $\mu 1$ stock DEAF-dextran $(20 \mathrm{mg} / \mathrm{ml}$, dissolved in TBS) was added and thoroughly mixed. The cells were rinsed with TBS, and the $0.5 \mathrm{ml}$ of the above mixture added directly to the cells. The cells were allowed to stand at room temperature for $20 \mathrm{~min}$, and $3.0 \mathrm{ml}$ DME containing 200 $\mu \mathrm{g} / \mathrm{ml} \mathrm{DEAE-dextran,} 10 \% \mathrm{NBCS}$, and penicillin-streptomycin was added. After $4 \mathrm{hr}$ at $37^{\circ} \mathrm{C}$ and $7 \% \mathrm{CO}_{2}$, the culture medium was removed and replaced with $2.5 \mathrm{ml}$ HEPES-buffered saline [137 IIm NaCl, 5 Inм $\mathrm{KCl}, 0.7 \mathrm{~mm} \mathrm{Na}_{2} \mathrm{HPO}_{4}, 6 \mathrm{~mm}$ dextrose, $21 \mathrm{~mm}$ HEPES ( $\mathrm{pH}, 7.1$ )] containing $10 \%$ dimethyl sulfoxide (DMSO). The cells were incubated in this solution for $2 \mathrm{~min}$ at room temperature, washed with HEPESbuffered saline, and allowed to recover under normal culture conditions.

Stable transfections. Stable transfectants were generated using either the Parker and Stark (1979) modification of the calcium phosphate transfection procedure originally described by Graham and van der Eb (1973) or the original procedure itself. In the former procedure, a 2-min DMSO shock replaces the original 5-min glycerol shock applied to cells after $4 \mathrm{hr}$ of exposure to the DNA-calcium phosphate complex. For most experiments, $10 \mu \mathrm{g}$ plasmid DNA linearized with ScaI was used per $100-\mathrm{mm}$ dish. After the shock treatment, the cells were allowed to recover for 2-3 d under normal culture conditions. The cells were split 1:10 onto 100-mm culture dishes and selected in DME containing 400 $\mu \mathrm{g} / \mathrm{ml} \mathrm{G} 418,10 \% \mathrm{NBCS}$, and penicillin-streptomycin. G418-resistant colonies were harvested with the aid of sterile cloning cylinders, expanded under selection conditions, and screened for the expression of NF protein.

Northern blotting. Total RNA was isolated from cultured cells by the quanidine isothiocyanate method of Chirgwin et al. (1979). Twenty micrograms of the isolated RNA was electrophoresed through a formaldehyde agarose gel and transferred onto GeneScreen membranes (NEN Davis et al., 1986). The blots were hybridized with ${ }^{35} \mathrm{P}$-dCTP-labeled cDNA probes generated by nick translation. A cDNA probe fully en- 
GM IIC CGE CGC CCG ICC CGO CCC CGC ACT CCC SCT CCG CCG SCO SCC SCA CCT GCT CCG 60

GCE ATG ATG AGC ITC GGC AGC OCC GAT GCG CTG CTG GOC OCC CCG TTC GCE CCO CTG CAC 120

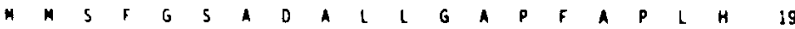

GGa GSa GSC AGC CIG CAC TAC GCG CIG AGC CGC MG GCA GGC GCC GOC GSC ACG CGC TCC 180

$\begin{array}{llllllllllllllllllllll}G & G & G & S & L & H & Y & A & L & S & R & K & A & G & A & G & G & T & R & S & 39\end{array}$

GCG GCC GGC ICC ICC AGC GCC IIC CAT ICG IGG GCG CGO ACG ICG GTG AGC ICC GTG TCC 240

$A$ A G S S S S S G $F$ F

GCT ICG CCC AGC CGC ITC CEC GGC GCC OCC ICG AGC ACC GAC TCG CTA GAC ACC CTA AGC 300

$A S P S A$ P R G A A S S T D S L D T L S 79

MT GGE CCA GAG GGC IGC GIG GCG GCG GTG GCG GCG CGC AGC GAG AAG GAG CAG CTG CAG 360

N G P E G C V A A V A A R S E K E Q L

GCG CTC MC GAC CGC TTC GCG GGC TAC ATC GAT AAG GTG AGG CAG CTT GAG GCG CAC AAC 420

A L N D $R$ R F $A$ G

CGC ACC CTG GAA GGC GAG GCG GCG GCG CTG CGG CAG CAG AAG GGC CGC GCC GCC ATG GGC R $T$ L $E$ G

GAG CTG TAC GAG CGC GAG GTG CGC GAG ATG CGC GGG GCC GTG CTG CGC CTG GGG GCG GCG 54

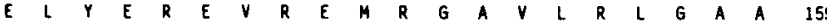

CGC GGG CAC GTG CGC CTG GAG CAG GAG CAC TTG CTG GAG GAC ATC GCG CAC GTC CGC CAG 600

$\begin{array}{lllllllllllllllllllll}R & G & H & V & R & L & E & Q & E & H & L & L & E & D & \text { I } & A & H & V & R & Q & 179\end{array}$

CGG CTG GAC GAG GAG GCC CGG CAG CGC GAG GAA GCG GAG GCG GCG GCC CGC GCC CTA GCG 660

$\begin{array}{lllllllllllllllllllllll}R & L & D & E & E & A & R & Q & R & E & E & A & E & A & A & A & R & A & L & A & 199\end{array}$

CGG IIC GCG CAG GAG GCG GAA GCG GCG CGC GTG GAG CTG CAG AAG AAG GCG CAG GCG CTG 720

$\begin{array}{lllllllllllllllllllll}R & F & A & Q & E & A & E & A & A & R & V & E & L & O & K & K & A & Q & A & L & 219\end{array}$

CAG GA GAG IGC GGC TAC CTG CGG CGC CAC CAC CAG GAG GAG GTG GGC GAG CTG CTC GGT 780 $\begin{array}{lllllllllllllllllllll}Q & E & E & C & G & Y & L & R & R & H & H & O & E & E & Y & G & E & L & L & G & 239\end{array}$

CAG AIT CAG GGC TGC GGT GCC GCG CAG GCG CAG GCT CAG GCC GAG GCT CGG GAC GCC CTC 840

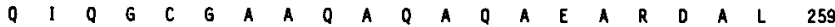

MG TGC GAC GTG ACG TCG GCG CTG CGG GAG ATC CGC GCG CAG CTC GAA GGA CAC ACG GTG 900 $\begin{array}{lllllllllllllllllllll}K & C & D & V & \text { T } & S & A & \text { L } & R & E & \text { I } & R & \text { A } & \text { Q } & \text { L } & \text { E } & G & \text { H } & \text { T } & V & 279\end{array}$

CAG AGT ACG CTG CAG TCA GAG GAG TGG TTC CGA GTG AGA TTG GAC CGA CTC TCA GAG GCA 960 $\begin{array}{lllllllllllllllllllll} & S & T & L & Q & S & E & E & W & F & R & V & R & L & 0 & R & L & S & E & A & 299\end{array}$

GCC MM GIG AAC ACG GAT GCT ATG CGC TCT GCC CAA GAG GAG ATA ACT GAG TAC CGG CG6 1020

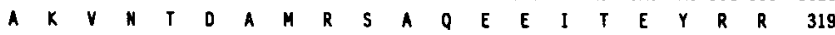

CAG CTG CAG GCC AGG ACC ACA GAG ITG GAG GCA CTG AMA AGC ACC MAG GAG ICA CTG GAG 1080 $\begin{array}{lllllllllllllllllllll}Q & L & Q & A & R & T & T & E & L & E & A & L & K & S & T & K & E & S & L & E & 339\end{array}$ AGG CAG CGC TCT GAG CTG GAG GAC CGT CAT CAG GTA GAC ATG GCC TCC TAC CAG GAT GCA 1140 R O R S E L E D R H O V D M A $S$ S Y ATT CAG CAG CTG GAC MT GAG CTG AGA MAC ACC MAA TGG GAG ATG GCC GCG CAG CTC CGA 1200 I $O$ O L D N E L R N T K N E N A A Q L R 379 GAG TAC CAG GAC CTG CTC AAC GTC AAG ATG GCC CTG GAT ATT GAG ATC GCT GCT TAC AGA 1260 E Y O

MA CTC CTG GAA GGC GMA GAG TGT CGG ATT GGC TTT GGA CCC AGT CCC TTC TCT CTT ACT 1320 $\begin{array}{lllllllllllllllllllll}K & L & L & E & G & E & E & C & R & I & G & F & G & P & S & P & F & S & L & T & 419\end{array}$ GAG GGA CTC CCC AMA ATT CCC TCC ATG TCC ACT CAC ATA MAA GTC MM AGC GAA GAG MAG 1380

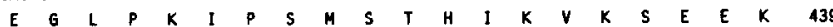

ATA MM GTA GTA GAA AMA TCG GAG AAG GAA ACC GTC ATT GTA GAG GM CAG ACA GM GAG 1440

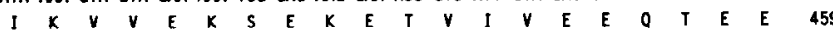
ATC CAG GTG ACA GAM GAA GTG ACA GAA GAG GAG GAC AAA GAG GCC CMA GGG GAG GM GAA 1500

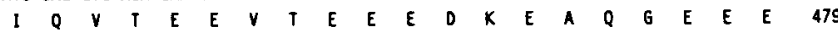

GM GAG GCA GM GAG GGA GGA GAA GAA GCA GCA ACT ACG TCT CCC CCT GCA GAM GAG GCT 1560 E E A E E G G E E A A GCA TCT CCA GAA AAG GAA ACC AAG TCT CCT GTG AMA GAA GAG GCC AAG TCC CCA GCT GAG 1620 $\begin{array}{lllllllllllllllllllll}A & A & E & K & E & T & K & S & P & V & K & E & E & A & K & S & P & A & 519\end{array}$ GCC MG TCC CCA GCT GAG GCC AAG TCA CCA GCT GAG GCC AMG TCC CCA GCT GAG GTC AAA 1680 A K S P A E A K K S P A E A K

TCT CCA GCT GAG GIC AMA TCT CCA GCT GAG GCC AAG TCA CCA GCT GAG GCC AAG TCA CCA 1740

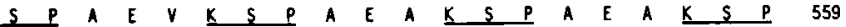

GCT GAG GIC MA ICT CCA GCT ACA GTG MG TCT CCA GCT GAG GCC MG ICA CCA GCT GAG 1800 A E V K S P A T V K S P A E A K S P A E 579 GCC MG TCA CCA GCT GAG GTC MA TCT CCA GCT ACA GTG MG TCT CCA GGT GAG GCC MG 1860 $A K S \quad P$ A E V K S P A T V K S P G E A K 599 TCC CCA GCT GAG GCC MG TCA CCA GCT GAG GTC MU TCT CCA GTG GAG GCC MG TCA CCA 1920 S P A E A K S P A E V K S P V E A K S P 619 GCT GAG GCC MG TCT CCA GCT TCA GTG MG TCC CCA GGT GAG GCC MG TCA CCA GCT GAG 1980 $A$ A A K S P A S V K S P $\quad$ S E A K S P A E 639 GCC MG TCA CCA GCT GAG GTC MA TCT CCA GCT ACA GTG MAG TCC CCA GTT GAG GCC MG 2040 $A \quad K S P A$ E $\vee \underline{K} S \quad P \quad A \quad T \quad \vee \quad K \quad S \quad P \quad \vee \quad E$ A 659 TCA CCA GCT GAG GTC AMA TCT CCA GTT ACA GTG MG TCC CCA GCT GAG GCC MG TCA CCA 2100

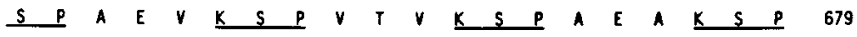
GTT GAG GTC AAA TCT CCA GCT TCG GTG AAG TCC CCA AGT GA GCC MG ICA CCA GCT GGA 2160

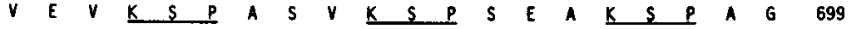

GCC AAG TCA CCA GCT GAG GCC AAG TCA CCA GTT GTG GCC MU TCA CCA GCT GAG GCC MG 2220

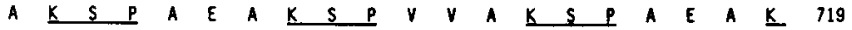
TCA CCA GCT GAG GCC AAG CCI CCA GCT GAG GCC MG TCA CCA GCT GAG GCC MG TCT CCA 2280 $\begin{array}{llllllllllllllllllll}S & P & A & E & A & K & P & P & A & E & A & K & S & P & A & E & A & K & S & P\end{array}$

GCT GAG GCC AAG TCT CCA GCT GAG GCC AAG TCA CCA GCT GAG GCC MG TCA CCT GIT GAG 2340 A E A K $S$ S A E A K S P A E A K S P V E 759 GTA AAA TCT CCA GAG AAG GCC AAG AGC CCC GTG AAG GM GGT GCA MM TCC CTA GCT GAG 2400 $\begin{array}{lllllllllllllllllllll}K & S & P & E & K & A & K & S & P & V & K & E & G & A & K & S & L & A & E & 779\end{array}$ GCC AAG ICC CCT GAG AAG GCC AAG TCC CCT GTG AAG GM GAG ATC MG CCT CCA GCT GAG 2460 $\begin{array}{lllllllllllllllllllll}A & K & S & P & E & K & A & K & S & P & V & K & E & E & I & K & P & P & A & E & 799\end{array}$ GTG AMA ICC CCC GAG AAG GCC MAG AGC CCC ATG MG GAG GAG GCC MG TCT CCT GAG MG 2520 $\begin{array}{lllllllllllllllllll}K & S & P & E & K & A & K & S & P & M & K & E & A & K & S & P & E & K & 819\end{array}$ GCC AAG ACI CTG GAT GTG AAG TCT CCA GAA GCC MG ACT CCA GCG MG GAG GM GCA MAG 2580 A K I L D $V$ V CGC CCC GCA GAC ATC AGA TCC CCT GAG CAG GTC MU AGT CCT GCC MG GAG GAG GCC MG 2640 $\begin{array}{lllllllllllllllllllll}R & P & A & D & I & R & S & P & E & Q & V & K & S & P & A & K & E & E & A & K & 859\end{array}$ ICC CCC GAG AAG GM GAG ACC AGG ACT GAA MG GTG GCT CCC MG MG GM GAG GTG MG 2700 $\begin{array}{lllllllllllllllllllll}5 & P & E & K & E & E & T & R & T & E & K & V & A & P & K & K & E & E & V & K & 879\end{array}$ TCC CCT GTG GAG GAG GTA MA GCC MA GM CCC CCA MG MG GTG GAG GAG GAG MG ACA 2760

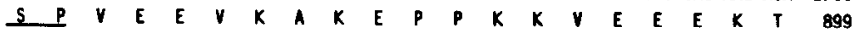

CCA GCC ACA CCA MG ACA GAG GTG MAG GAG AGC MG MA GAT GM GCT CCC MG GAG GCC 2820 $\begin{array}{lllllllllllllllllllll}P & A & T & P & K & T & E & V & K & E & S & K & K & D & E & A & P & K & E & A & 919\end{array}$ CAG MG CCC MG GCG GAG GAG MG GAG CCT CTC ACA GMA MG CCC MG GAC TCT CCG GGG 2880 $\begin{array}{lllllllllllllllllllll}O & K & P & K & A & E & E & K & E & P & L & T & E & K & P & K & 0 & S & P & 6 & 939\end{array}$ GM GCC MAG MAG GAA GAG GCT MA GAG MG MG GCG GCG ECC CCA GAG GA6 GAG ACG CCC 2940 E A K K K $E$ E $E$ A $A$ K E GCC MGG TTG GGC GTG MAG GM GAG GCT MU CCC MA GAG MG GCA GM GAC GCC MG GCC 3000 A K $L \quad G \quad V \quad K$ E E A K P K E K A E D A K A

AM GAA CCT AGC AAA CCC TCA GMA MAG GAG MA CCG MG MG GAG GAG GTG CCG GCA GCA 3060

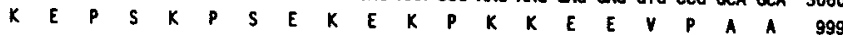
CCA GAG AAG AAA GAC ACC MAG GAG GAG MAG ACT ACG GAG TCC MG MG CCT GAG GAG MA 3120

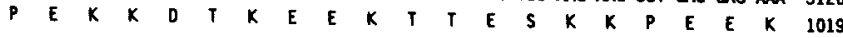
CCC MA ATG CAG GCC AAG GCC AAG GAG GAG GAC MG GGC CTT CCC CM GAG CCT AGC MA 3180

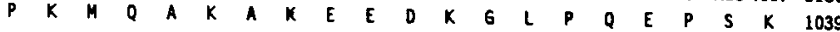
CCC MGG ACA GAA AAG GCT GAA AAG ICC ICT AGC ACA GAC CM MM GAC AGC CAG CCC TCA 3240

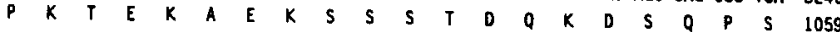
GAG AMG GCC CCA GAG GAC AAG GCT GCC AAG GSA GAC MG TM GAG GAC GAG AGG GAC ACC 3300

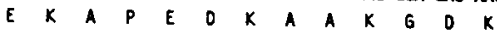
1072

CAG AAT AGC CCA AGA AAC. TCA GGA CGG CCC CGG TAC TCA AGG GTT GGT GTA ATA AAG TTT 3360

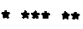

AIT ICT TCC TTT CCC TCC GTA AGA AGA AAC ACC ACT GGA AIT C

3403 
coding for rat $\beta$-actin was obtained from Dr. Debra Leonard (New York University Medical Center, NY) and used as a normalization control.

Immunofluorescence. Cells were cultured on untreated sterile glass coverslips and, after the appropriate experimental procedures were performed, were fixed with freshly prepared 10\% formalin in Dulbecco's phosphate-buffered saline deficient in $\mathrm{Ca}^{2+}$ and $\mathrm{Mg}^{2+}$ (PBS-DEF) for $20 \mathrm{~min}$ at room temperature. The coverslips were rinsed several times with PBS-DEF, and the cells were permcabilized with cold $\left(20^{\circ} \mathrm{C}\right)$ absolute methanol for $10 \mathrm{~min}$. After washing with several changes of PBS-DEF, the coverslips were incubated with 3\% normal goat serum for $30 \mathrm{~min}$. Primary antibodies were applied and incubated for $1 \mathrm{hr}$ at room temperature. Appropriate secondary antibodies conjugated with either FITC or TRITC were applied after washing with PBS-DEF. After $0.5-1 \mathrm{hr}$, the coverslips were washed thoroughly with PBS-DEF and mounted in a polyvinyl alcohol-based mountant (Rodriguez and Deinhardt, 1960; Blose, 1981). Preparations were viewed with a Nikon Optiphot equipped with a $100-\mathrm{W} \mathrm{Hg}$-lamp epifluorescence attachment. Photographs were taken with Kodak T-Max 400 black and white negative film exposed at ASA 400.

Cytoskeleton preparation. Cultures were rinsed 3 times with Dulbecco's phosphate-buffered saline deficient in $\mathrm{Ca}^{2+}$ and $\mathrm{Mg}^{2+}$ (PBS-DEF) and harvested by scraping with a rubber policeman, followed by lowspeed centrifugation. Cell pellets were resuspended and homogenized in an ice-cold $\left(4^{\circ} \mathrm{C}\right)$ buffer composed of $10 \mathrm{~mm}$ phosphate $(\mathrm{pH}, 6.8), 0.1$ mM EDTA, $1 \%$ Triton X-100, $0.5 \mathrm{mg} / \mathrm{ml}$ DNase I (Worthington Biochemical Corp., Freehold, $\mathrm{NJ}$ ), $10 \mathrm{mM} \mathrm{MgCl}_{2}$, and $2 \mathrm{~mm}$ phenylmethylsulfonyl fluoride (PMSF; Sigma, St. Louis, MO). The homogenates were allowed to stand at room temperature for $10-30 \mathrm{~min}$ and were spun in an Eppendorf microcentrifuge to recover Triton X-100-insoluble pellets and supernatants. The 2 fractions were then analyzed by SDS-PAGE and Western blot analysis.

Electrophoresis and immunoblotting. One-dimensional SDS-PAGE was performed by the use of the discontinuous buffer system of Laemmli (1970) on $6 \%$ polyacrylamide slab gels. Samples were solubilized by boiling in sample buffer with a final working dilution of $62.5 \mathrm{~mm}$ Tris $(\mathrm{pH}, 6.8), 1 \%$ SDS, $1 \% \beta$-mercaptoethanol, and 10\% glyccrol. Gcls designated for immunoblotting were overlayed with sheets of nitrocellulose filters (Schleicher and Schuell, Inc., Keene, NH), and the proteins were electrophoretically transferred onto the nitrocellulose filters using a Bio-Rad Transblot apparatus following a modification of the method of Towbin et al. (1979). After the proteins were transferred onto the nitrocellulose filters, the filters were preincubated in either 5\% BSA in PBS-DEF or $10 \%$ nonfat dry milk in PBS-DEF. The blots were incubated with primary antibodies for varying amounts of time, washed extensively with PBS, then incubated with horseradish peroxidase-conjugated secondary antibodies (Hyclone). Immunopositive bands were visualized by development with diaminobenizidine- $\mathrm{HCl}$ (Sigma) in the presence of hydrogen peroxide.

Alkaline phosphatase treatment. Transfected cells grown on glass coverslips were fixed in freshly prepared $10 \%$ formalin in PBS-DEF for 20 min at room temperature. After several rinses with PBS-DEF, the cells were permeabilized with $0.5 \%$ Triton $\mathrm{X}-100$ in PBS-DEF. The cells were thoroughly rinsed with PBS-DEF, then with $50 \mathrm{~mm}$ Tris- $\mathrm{HCl}(\mathrm{pH}$, 8.0 ) and $150 \mathrm{~mm} \mathrm{NaCl}$. Dephosphorylation was accomplished with 40 $\mathrm{U} / \mathrm{ml}$ alkaline phosphatase (type III-N, Sigma) in $50 \mathrm{~mm}$ Tris- $\mathrm{HCl}(\mathrm{pH}$, 8.0), $150 \mathrm{~mm} \mathrm{NaCl}, 1 \mathrm{mM} \mathrm{MgCl}, 0.1 \mathrm{mM} \mathrm{ZnSO}_{4}$, and $1 \mathrm{~mm}$ PMSF at $37^{\circ} \mathrm{C}$ for $2.5 \mathrm{hr}$. After this treatment, the cells were thoroughly washed with PBS-DEF and stained for immunofluorescence.

Immunoelectron microscopy. Cells were grown on 35-mm sterile plastic culture dishes (Costar, Cambridge, MA). The cultures were washed extensively with PBS-DEF and fixed with freshly prepared $4 \%$ paraformaldehyde (w/v) in PBS-DEF at $\mathrm{pH} 7.4$ for $30 \mathrm{~min}$ at room temperature. The cells were washed several times with PBS-DEF and permeabilized with $0.5 \%$ Triton X-100 in PBS-DEF for $10 \mathrm{~min}$ at room temperature. After rinsing with PBS-DEF, the cells were treated with $3 \%$ normal goat serum in $1 \%$ BSA-PBS-DEF at room temperature for $30 \mathrm{~min}$. Primary antibodies diluted in 1\% BSA-PBS-DEF were applied and the cells incubated at $4-8^{\circ} \mathrm{C}$ overnight. The cells were thoroughly rinsed with $1 \%$ BSA-PBS-DEF and secondary antibodies conjugated to colloidal gold particles of either 5- or $15-\mathrm{nm}$ sizes were applied. The cells were incubated with the labeled secondary antibody at room temperature with shaking for 1-2 hr. Specimens that were processed for double staining were sequentially reacted with the individual primary antibodies, then with colloidal-gold-labeled secondary antibodies, again sequentially applied, first with the larger gold particles, then with the smaller oncs. The samples werc processed for conventional transmission electron microscopy, first by fixation in $1 \%$ glutaraldehyde in PBS-DEF for $1 \mathrm{hr}$ at room temperature, followed by thorough washing with PBSDEF. Cells were postfixed with $1 \%$ osmium tetroxide in PBS-DEF, rinsed thoroughly with PBS-DEF, then with $50 \mathrm{~mm}$ maleate buffer $(\mathrm{pH}$, 5.2). The cells were stained with $1 \%$ uranyl acetate in maleate buffer $(\mathrm{pH}, 5.2)$ for $1 \mathrm{hr}$, dehydrated through graded ethanols, and infiltrated and embedded in Spi-pon 812 epoxy resin (Spi Supplies, West Chester, PA). Sections were cut on a Sorvall MT5000 ultramicrotome using a Diatome diamond knife. Gold-silver sections were collected onto $200-$ mesh copper grids, stained with aqueous uranyl acetate and Reynolds' (1963) lead citrate, and viewed on a JEOL $100 \mathrm{C}$ electron microscope operating at $80 \mathrm{kV}$.

\section{Results}

cDNA clone encoding the $N F-H$ subunit of rat neurofilaments A 3.4-kb cDNA clone was isolated from our rat-brain $\lambda \mathrm{gt} 11$ library by high-stringency DNA hybridization and was subsequently subcloned into pGEM-3, M13mp18, and M13mp19. Translational start and stop codons were identified from DNA sequencing, indicating that we had isolated a fully encoding rat NF-H cDNA clone (Fig. 1). This clone included 57 base pairs of the $5^{\prime}$-untranslated region and 115 base pairs of the 3 '-untranslated region. A consensus polyadenylation signal sequence was located 60 base pairs downstream from the translational stop codon. Partial rat NF-H cDNA sequence data have previously been reported. The most extensive sequence by Breen et al. (1988) starts at position 236 of the NF-H protein, but diverges at position 1023, presumably because of a frame shift. A sequence by Dautigny et al. (1988) spans position 271 to the end of the protein sequence, whereas Lieberburg et al. (1989) reported the sequence from position 576 to the end of the NF-H protein.

Homology comparison of our deduced rat NF-H amino acid scquence demonstratcd an overall similarity of $88 \%$ with that of the deduced mouse NF-H protein (Julien et al., 1988; Schneidman et al., 1988). The head domains of these species were $100 \%$ identical, while the rod domain was $99 \%$ identical, with 7 amino acid replacements and 1 deletion. The dissimilarities in the tail regions were due to 102 replacements, 17 insertions, and 1 deletion within the mouse NF-H tail domain. Comparison with human NF-H showed an overall homology of $72 \%$ (Lees et al., 1988). The head and rod domains of human NF-H were highly similar with that of the rat with a combined homology of $98 \%$, resulting from 23 replacements and 3 insertions. The tail domain was only $58 \%$ homologous with that of the rat due to 123 replacements, 48 insertions, and 105 deletions. These comparisons are illustrated in Figure 2.

Sequence data indicates that rat NF-H is 1072 amino acid residues in length and has a predicted molecular mass of 115.3 $\mathrm{kDa}$, which is $42 \%$ lower than what is observed by SDS-PAGE (200 kDa for rat NF-H) but is in good agreement with reported

Figure 1. Complete nucleotide and deduced amino acid scquences of rat NF-H cDNA. The bar over bases 346-1287 indicates the location of the helical rod domain within the protein. The neurofilament-specific phosphorylation consensus tripeptide (KSP) sequences are underlined. Asterisks mark the position of a consensus polyadenylation signal sequence. The first and last 7 nucleotides are derived from EcoRI linkers used in the preparation of the cDNA library. 


\begin{abstract}
$\begin{array}{llllllllllllllll}1 & 10 & 20 & 30 & 40 & 50 & 60 & 70 & 80 & 90 & 100 & 110 & 120 \quad 130 & 140 & 150 & 160\end{array}$

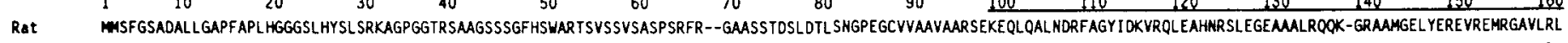

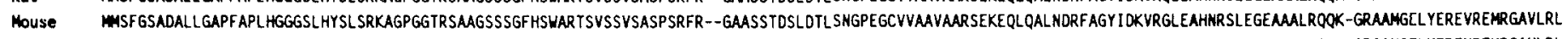

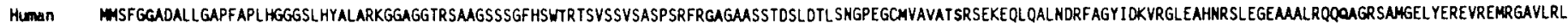
Porcine

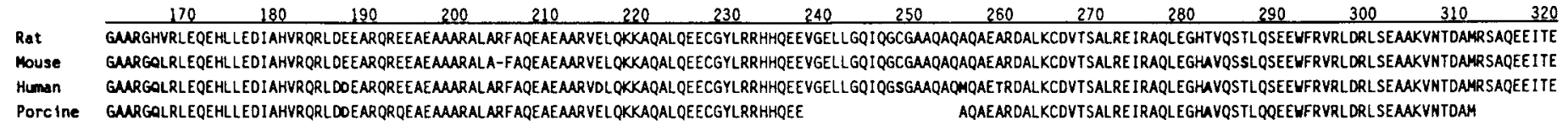

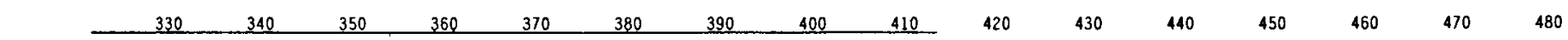

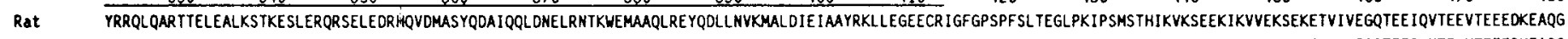

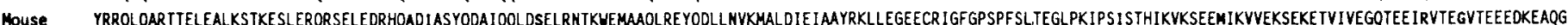

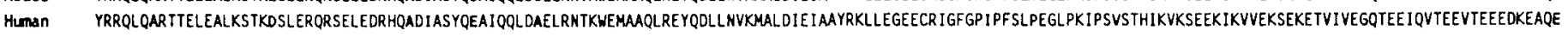

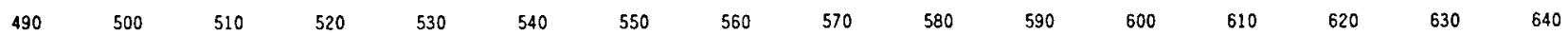

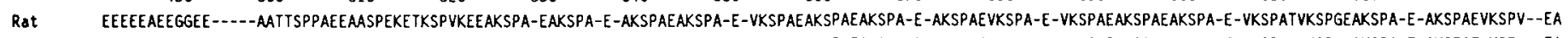

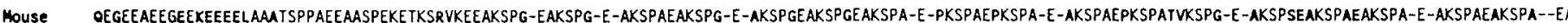

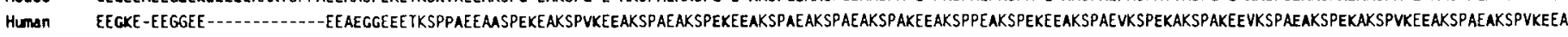

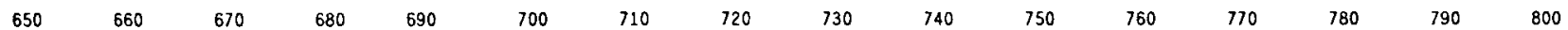

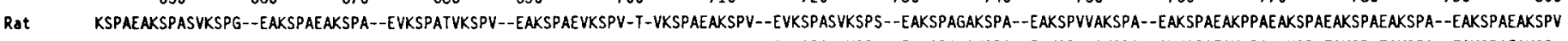

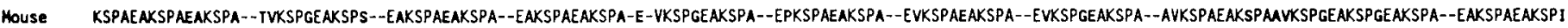

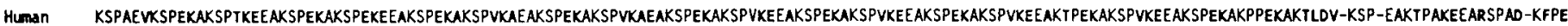

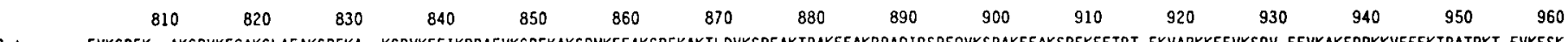

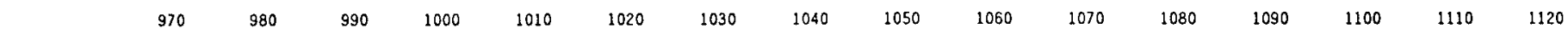

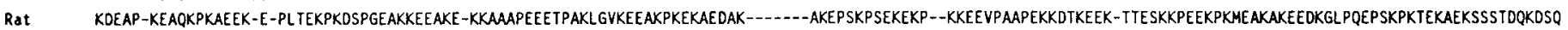

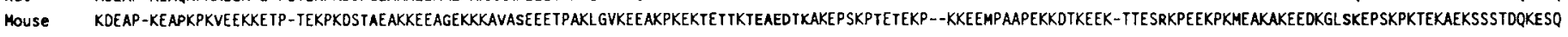

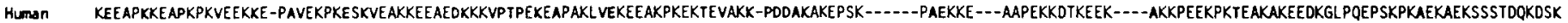

1120

Rat PSEKAPEOKAAKGDK
Mouse PPEKTIEDKATKGEK

Human PPEKATEDKATKGEK

Figure 2. Homology comparison of our deduced rat NF-H amino acid sequences with that of other reported NF-H sequences. The alignments were made by visual inspection. Dashes were inserted to maximize alignments. Residues that differ from that of our sequences (topmost rows) are printed in slightly smaller type. The bar above a portion of the sequence represents the $\alpha$-helical rod domain. Mouse, Schneidman et al. (1988) and Julien et al. (1988); human, Lees et al. (1988); porcine, Geisler et al. (1983).

values obtained by gel filtration and sedimentation equilibrium centrifugation, $138 \mathrm{kDa}$ and $112 \mathrm{kDa}$, respectively (Kaufmann et al., 1984). The predicted pI value was 6.4 , which is more acidic than what has been observed (pI, 7.2) for nonphosphorylated rat NF-H reported by Oblinger (1987).

\section{In Vitro transcription translation}

The fully encoding rat NF-H cDNA clone was subcloned into pGEM-3 such that transcription from the T7 promoter generated RNA transcript, which when subsequently translated in vitro in a rabbit reticulocyte lysate system yields a protein that migrates at an apparent molecular mass of approximately 180 $\mathrm{kDa}$ (Fig. $3 A$ ). This result is consistent with the reported mobility for unphosphorylated NF-H protein (Carden et al., 1985; Lewis and Nixon, 1988).

Two dimensional NEPHGE-PAGE analysis of radiolabeled in vitro transcribed and translated rat NF-H protein indicated an isoelectric point of approximately pI 7 (Fig. $3 B$ ), which is in good agreement with the value reported by Oblinger (1987) for in vivo labeled NF-H.

\section{Plasmid constructs}

Eukaryotic expression plasmids pRSVi-NFH $2 \mathrm{~A}(+)$ and pSV2i$\mathrm{NFH} \mathrm{lA}(+)$ were constructed in which the rat NF-H cDNA insert was subcloned behind strong constitutive viral promoters in the sense orientation in the same manner as described before for NF-L and NF-M (Chin and Liem, 1989). The plasmids pRSV-NFH 2A(+)neol, pSV2i-NFH $1 \mathrm{~A}(+)$ neol, pRSVI-NFH $5 \mathrm{~A}(-)$ neol, and pSV2i-NFH $4 \mathrm{~A}(-)$ neo 5 were the corresponding constructs that incorporated a SV40 promoter-driven neomycin gene (Chin and Liem, 1989).

\section{Transient transfections}

Transient transfections of $\mathrm{L} \mathrm{tk}^{-}$and Cos cells resulted in approximately $10-30 \%$ of the cells treated with the sense constructs pRSVi-NFH $2 \mathrm{~A}(+)$ and pSV2i-NFH $1 \mathrm{~A}(+)$ being positively stained with the $\mathrm{mAb}$ SMI 32, which recognizes nonphosphorylated NF-H and NF-M. The transfected, nonphosphorylated NF-H was distributed within the cytoplasm in a filamentous pattern (Fig. 4A, B). Focal, juxtanuclear staining observed in NF-L and NF-M transfectants (Chin and Liem, 1989) was not apparent in NF-H transfected cells, except at $24 \mathrm{hr}$ post-transfection (see below).

When NF-H-transfected cells were stained with mAbs that recognize phosphorylated NF-H epitopes (SMI 31, NF2, and BMB NF200), a very small subpopulation $(<1 \%)$ of the transfcctcd cclls was spccifically staincd cither in a cytoplasmic dotlike manner or in a filamentous pattern (Fig. $4 C, D$ ). All of the 


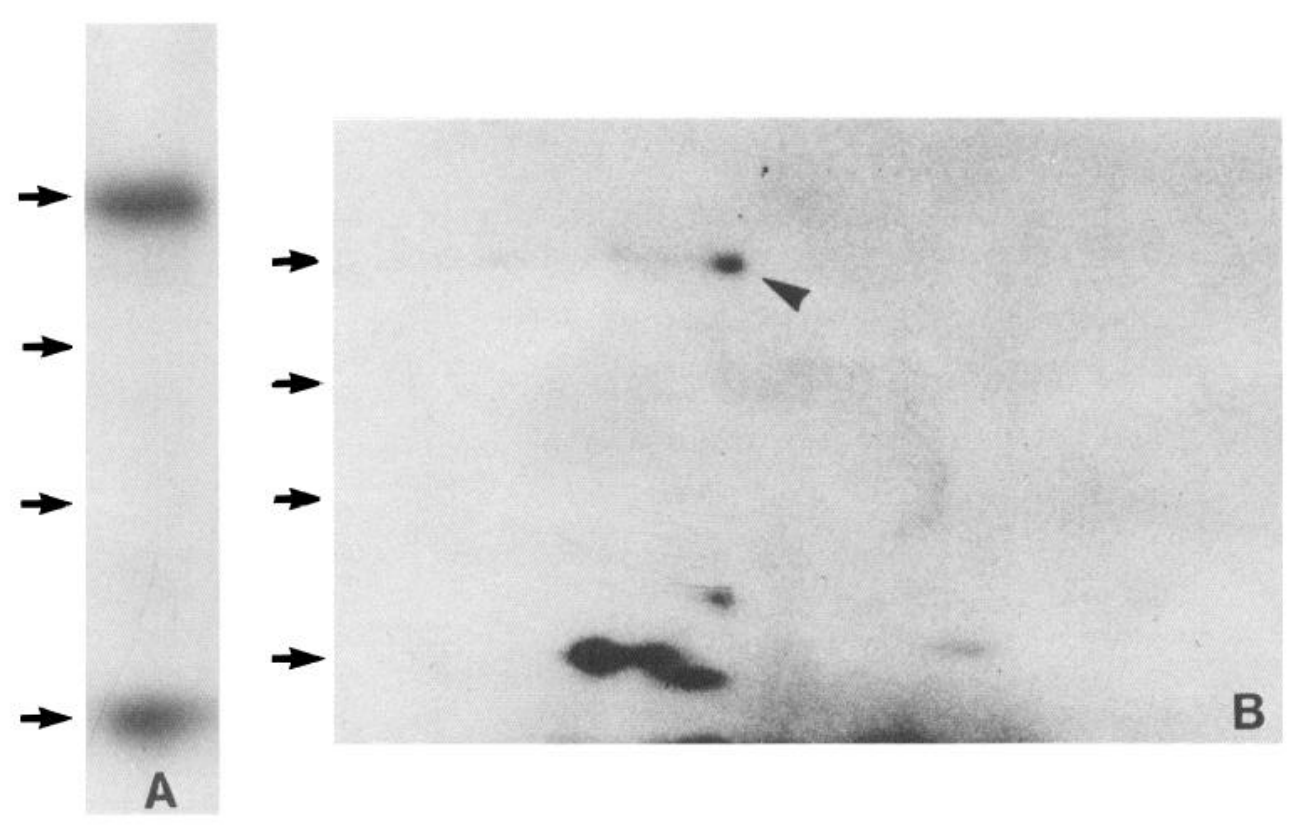

Figure 3. Analysis of in vitro transcribed and translated proteins from rat NF-H cDNA cloned into pGEM-3. Translation of cRNA generated from transcription with T7 RNA polymerase resulted in the synthesis of protein that migrated slightly below $180 \mathrm{kDA}$ on $6 \%$ SDS-PAGE ( $A$, lane 1); the lower band at $\sim 49 \mathrm{kDa}$ is a nonspecific translation product also seen in the water control (not shown). Two-dimensional NEPHGE-PAGE analysis of the protein $(B)$ demonstrated that the $\mathrm{pI}$ of in vitro translated rat NF-H (arrowhead) is approximately 7 (the basic end of the gel is on the right). The molecular-mass markers indicated by arrows are from top to bottom, 180, 116, 84, and $49 \mathrm{kDa}$. cells, however, demonstrated the nonspecific nuclear staining characteristic of this type of antibody (Wood et al., 1985).

\section{Stable transfections}

Stable transfection of $\mathrm{L} \mathrm{tk}^{-}$and 3T6 cells resulted in G418resistant clones, some of which were immunoreactive with $\mathrm{mAb}$ SMI 32. Treatment with the plasmid pRSVi-NFH $2 \mathrm{~A}(+)$ neol resulted in 11 of 18 clones examined from each of the $\mathrm{L} \mathrm{tk}^{-}$and $3 \mathrm{~T} 6$ transfections and 8 of 21 clones from the $\mathrm{L} 929$ transfections being positive for NF-H staining. Transfections with the plasmid pSV2i-NFH $1 \mathrm{~A}(+)$ neol resulted in 17 of $24 \mathrm{~L} \mathrm{tk}^{-}$clones, 7 of $183 \mathrm{~T} 6$ clones, and 3 of $18 \mathrm{~L} 929$ clones stably expressing NF-H protein.

Stable transfections of L929 cells with pRSVi-NFM1(+)-neol (Chin and Liem, 1989) resulted in a number of NF-M-expressing cell lines, one of which (L929-S-M 10) was used for further studies.

\section{Northern blot analysis of stable transfectants}

Northern blot analysis of stably transfected clones that exhibited NF-H staining showed varying amounts of NF-H mRNA (Fig. 5). On the basis of these experiments, we used the L-S-H 1 and L929-S-H 15 cell lines for further characterizations by immunocytochemistry and Western blotting as described below.

\section{Immunostaining of stable $\mathrm{NF}-\mathrm{H}$ transfectants}

Stable L tk--derived NF-H transfectants (Fig. $6 A$ ) exhibited a fine filamentous staining pattern similar to that seen in the NF-H transient transfections. The prominently staining juxtanuclear focus present in most of the NF-M transfectants (Chin and Liem, 1989) was not observed in the NF-H clones. This evenly dispersed NF-H staining colocalized with vimentin staining (Fig. $6 B$ ). Stable transfectants derived from 3T6 cells showed essentially the same filamentous pattern as previously seen with the 3T6-derived NF-M stables. NF-H staining was similarly colocalized with vimentin filaments (Fig. 6C,D).

When the NF-H stable transfectants were immunostained with the phosphorylation-dependent mAb SMI 31, mAb BMB
NF200, or mAb NF2B3 (Liem et al., 1985), results were similar to those described above for the transient transfectants. The only staining present was in a few isolated cells that numbered $\ll 1 \%$ of the total cell population.

\section{Immunoblot analysis of transfected cells}

Immunoblot analysis of cells stably transfected with NF-H confirmed that the protein is in a predominantly nonphosphorylated form. The transfected NF-H protein migrated at an apparent molecular weight of $180 \mathrm{kDa}$, which is faster than the control NF-H protein from the rat optic nerve (Fig. $7 A$ ). Immunoblotting with mAbs SMI 31 (anti-phosphorylated NF) or SMI 32 (anti-nonphosphorylated NF) indicated that 2 different stably transfected NF-H cell lines are SMI 32 immunoreactive (Fig. $7 A$ ), but appear to be negative for SMI 31 (Fig. $7 B$ ), confirming the immunofluorescence data that NF-H in these cell lines is predominantly nonphosphorylated. For these experiments, we loaded identical amounts of cytoskeletal extracts of the cell lines on 2 lanes of the same gel. In order to determine whether we would have detected small amounts of SMI 31-immunoreactive material, we carried out a concentration-dependent blot with the 2 antibodies using purified NF-H. In these experiments, we found that SMI 31 could detect a 25 -fold lower concentration of NF-H. We also estimated the amount of NF-H from the cell extracts that was loaded on these gels by dot blot analysis and compared this amount with the sensitivity of SMI 31 and SMI 32 . We found that we could easily have seen the amount of NF-H loaded on the gels by both antibodies, even if $1 / 50$ the amount had been loaded. Thus, these results indicate that, within the limits of detection, there was no apparent SMI 31-reactive material in the cytoskeletal extracts. If NF-H is present in the predominantly nonphosphorylated form, we would expect that its isoelectric point would be close to $\mathrm{pI} 7$. Immunoblotting of cytoskeletal proteins from stably transfected cell line L929-S-H 15 separated by 2 -dimensional NEPHGE-PAGE confirmed this prediction and showed that the pI value of the NF-H protein was approximately 7.0 (Fig. $4 B$ ).

These results are in marked contrast to what was observed 

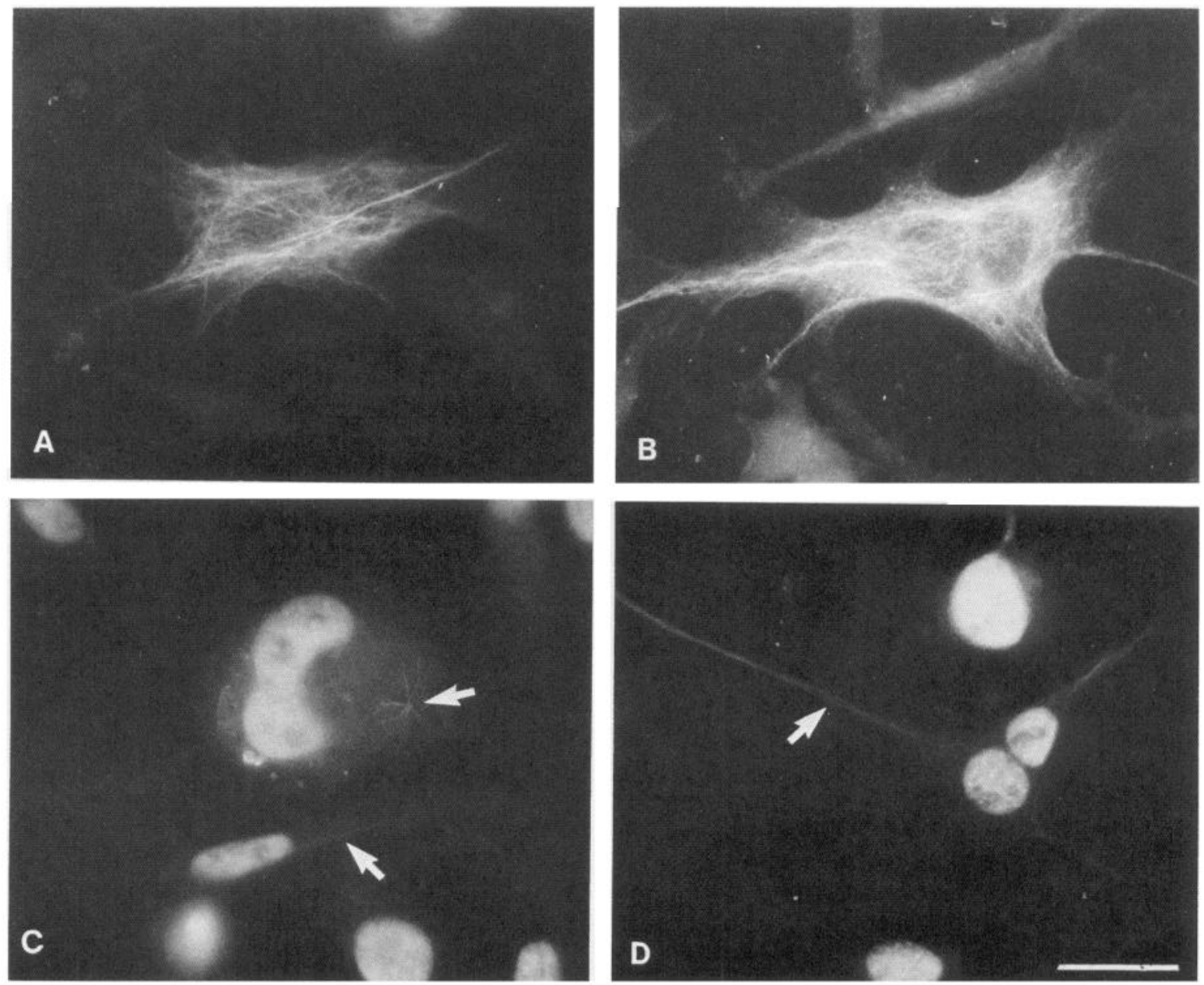

Figure 4. Immunofluroescent staining of $\mathrm{L} \mathrm{tk}^{-}$cells transiently transtected with $\mathrm{NF-H}$ constructs with antibodies sensitive to phosphorylation states of NF-H. $A$ and $B$, These cells were stained with mAb SMI 32 (anti-nonphosphorylated NF) $48 \mathrm{hr}$ after transfection and demonstrated a fine filamentous network. $C$ and $D$, The occurrence of cells stained with phosphorylation-dependent mAb SMI $3172 \mathrm{hr}$ after transfection was rare. Arrows point to the short $(C)$ and frequently faint $(D)$ filaments occasionally observed with mAb SMI 31 staining of these transfected cells. Characteristic nonspecific nuclear staining is clearly evident in all cells stained with mAb SMI 31 . Scale bar, $25 \mu \mathrm{m}$.

\section{$\begin{array}{llllllllll}C & 1 & 2 & 3 & 4 & 5 & 6 & 7 & 8 & 9\end{array}$}

23S-

18S-

235-

18S-

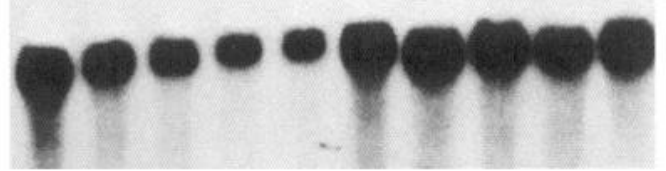

with transfected NF-M. Transfected rat NF-M were consistently reactive with both mAb SMI 32 and SMI 31, indicating that this protein is phosphorylated (Fig. $7 A, B$ ). These results are also consistent with the immunofluorescent staining described below.
Figure 5. Northern blot analysis of cell lines stably transfected with NF-H. Cell lines stably transfected with the NF-H-expression constructs and demonstrating NF-H staining were analyzed for the expected presence of NF-H mRNA. The top panel demonstrates the presence of NF-H hybridizing bands. The relative amounts of this NF-H transcript are noticeably variable, in some lanes, being barely detectable. The bottom panel shows the same filter hybridized with a rat $\beta$-action probe. Lane $C$ contains total RNA prepared from untransfected $\mathrm{L} \mathrm{tk}^{-}$cells. Lane 1, L-S-H 1; lane 2, L-S-H 6; lane 3, L-S-H 9; lane 4, L-S-H 12; lane 5, L-S-H 23; lane 6, L929-S-H 15; lane 7, L929-R-H 11; lane 8, L929-R-H 19; lane 9, 3T6-R-NFH 17. The abbreviations denote cell lines $\mathrm{L} \mathrm{tk}^{-}(L), \mathrm{L} 929$, and $3 \mathrm{~T} 6$ transfected with NF-H driven by the SV40 $(S)$ or RSV $(R)$ promoters. $23 S$ and $18 S$ mark the positions of the large and small ribosomal RNAs, respectively. 

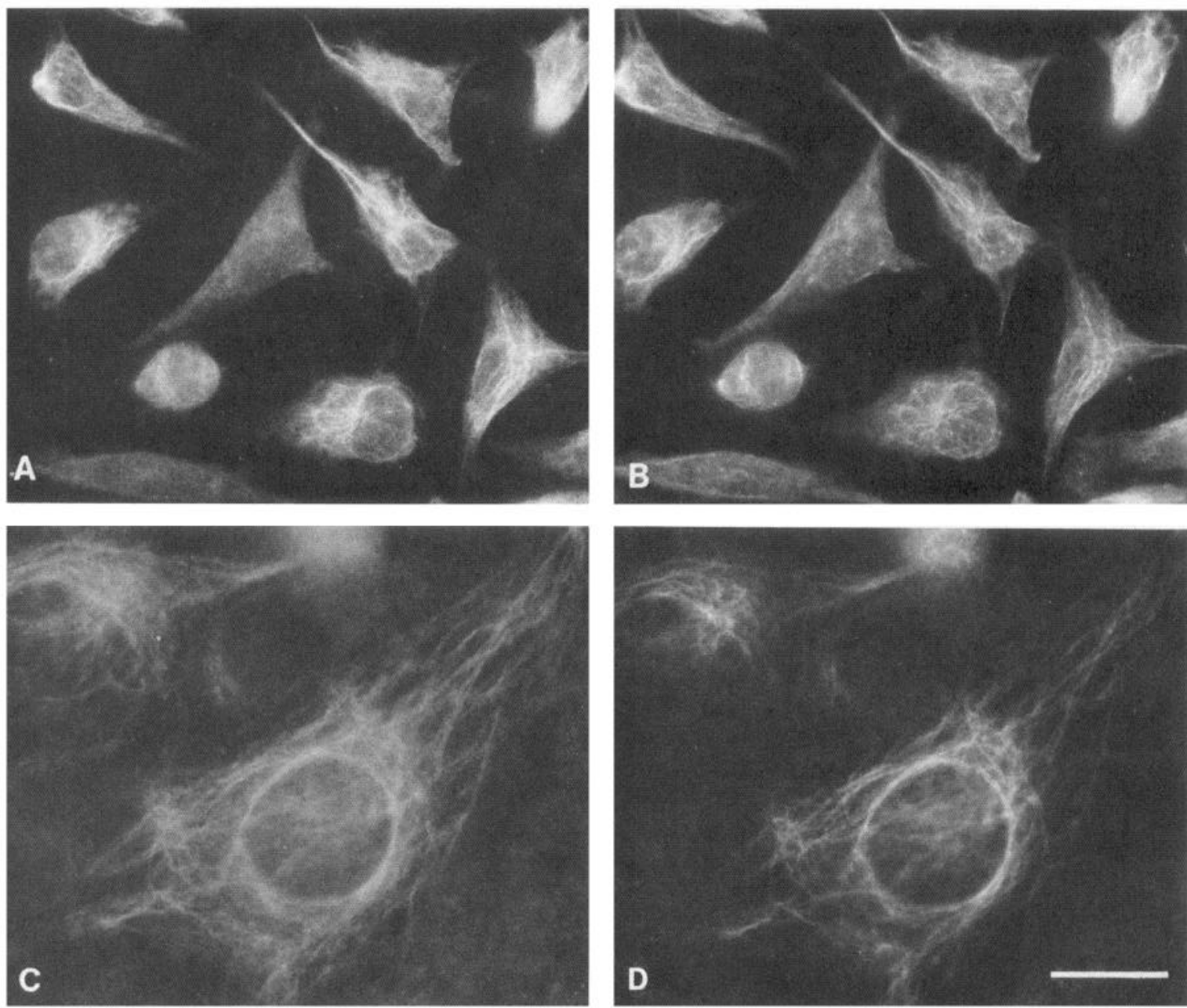

Figure 6. Double immunofluorescence staining of cells stably transfected with NF-H-expression constructs with antibodies to NF-H and vimentin. $A$, L-S-H 1 cells stained with mAb SMI 32 and followed by a TRITC-labeled goat anti-mouse IgG secondary antibody. $B$, The same field of cells as in $A$ but stained with a rabbit anti-vimentin antibody followed by an FITC-labeled goat anti-rabbit IgG secondary antibody. $C$ and $D$, Cell line 3T6-R-H 17 stained in the same manner as described in $A$ and $B$, respectively. Colocalization of NF-H and vimentin is apparent. Scale bar, $25 \mu \mathrm{m}$.

\section{Phosphorylation-dependent immunofluorescence of stably transfected $N F-M$ cells}

The cell lines L-S-M 15-1 (Chin and Liem, 1989) and L929-S-M 10 showed strong staining with SMI 31 in most $(>85 \%)$ of the cells and were used for further studies (Fig. $8 A$ ). Characteristic nonspecific nuclear staining was again seen in all cells stained with this antibody.

Because mAb SMI 31 specifically reacts only with the phosphorylated forms of NF-M and NF-H, the above results indicated that the former protein was being phosphorylated in vivo, while the latter was not. To confirm that the observed staining was indeed due to phosphorylation of the transfected protein, we did the following experiment. We treated fixed and permeabilized L-S-M $15-1$ cells with $40 \mathrm{U} / \mathrm{ml}$ E. coli alkaline phosphatase for $2.5 \mathrm{hr}$ at $37^{\circ} \mathrm{C}$, then stained these cells with mAbs SMI 31 and BMB NF160 (Fig. 8B,C). The dephosphorylated cells retained immunoreactivity with the phosphorylation-independent antibody mAb BMB NF160 (Fig. 8C), but did not demonstrate any specific cytoplasmic staining with mAb SMI 31: only the nonspecific nuclear staining remained (Fig. $8 B$ ).
The failure to remove the nonspecific nuclear staining indicates that these epitopes were apparently not affected by the alkaline phosphatase treatment. Because the filamentous staining pattern with mAb BMB NF160 was not altered in any way by the alkaline phosphatase treatment, we can confidently conclude that abolishment of SMI 31 immunoreactivity was due to dephosphorylation of the NF protein and not to some proteolytic activity.

\section{Time course of expression}

The patterns of NF-H staining were studied at different times after the transient transfection procedure. Time points of 6,12 , $18,24,48$, and $72 \mathrm{hr}$ after DMSO shock treatment were examined. Staining was first discernable at about $18-24 \mathrm{hr}$ (Fig. $9 A$ ). The staining consisted of a focal spot localized next to the cell nucleus, which was most noticeable in the Cos cell lines. Short NF-H-immunopositive filaments were observed to radiate out from this spot in some cells of the earlier time points but became more obvious after $48 \mathrm{hr}$. Closer examination of this focus revealed that this structure was composed of what appeared to be a spherically arranged coil of filaments. Addi- 


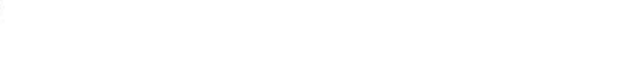

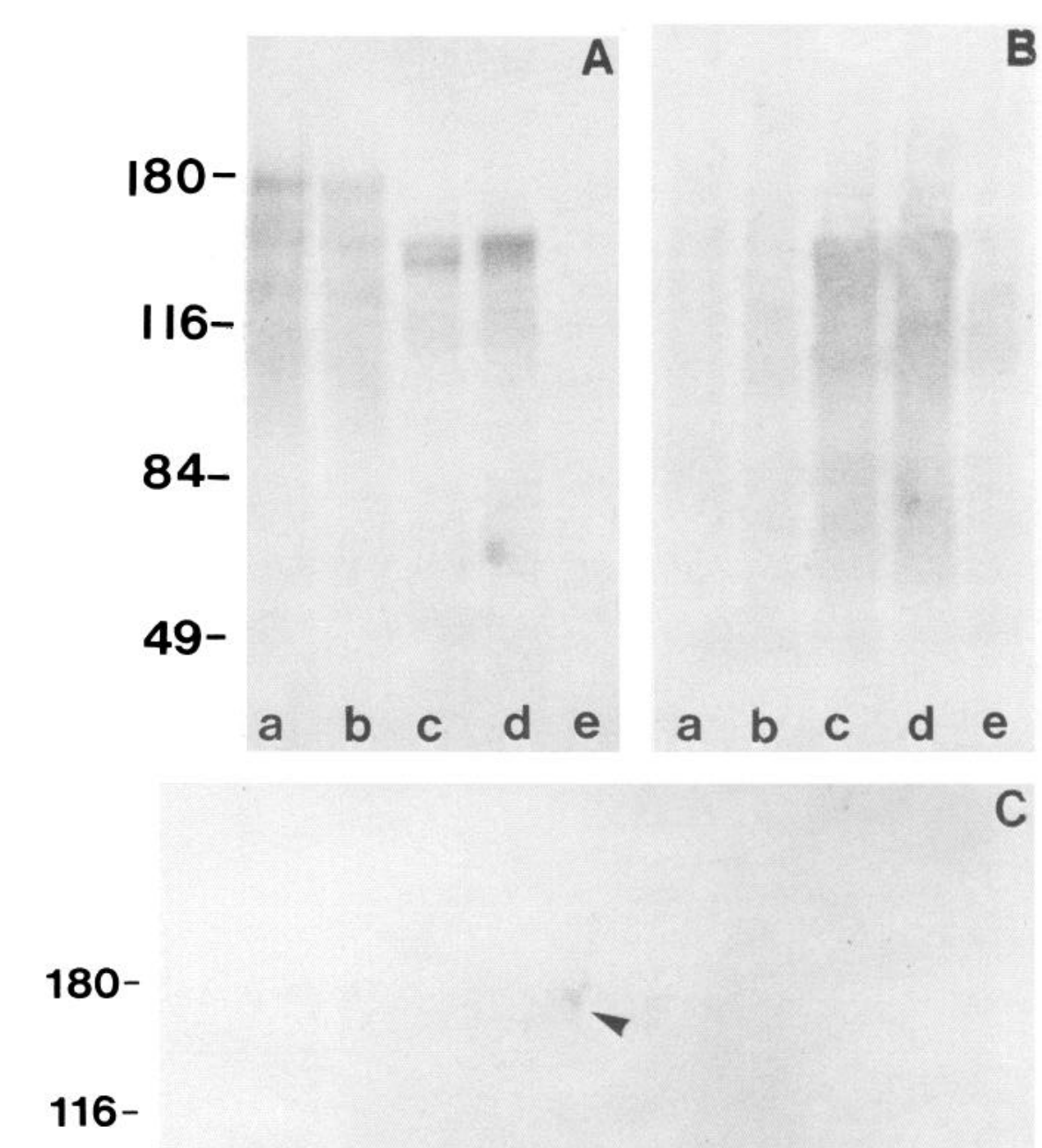

Figure 7. Immunoblot analysis of cytoskeletal preparations from cells stably transfected with NF-H or NF-M. Triton X-100-insoluble cytoskeletal material was prepared and analyzed. Lanes $a-e$ in $A$ were immunoreacted with the phosphorylation-dependent mAb SMI 31 , and lanes $a-e$ in $B$ were immunorected with mÁb SMI 32 (anti-nonphosphorylated NF). Lanes $a$, L-S-H 1; lanes $b$, L929-S-H 15; lanes $c$, L-S-M 15 ; lanes $d$, L929-S-M 10. Lanes e contain material from untransfected $\mathrm{L}$ tk cells. SMI 31, the phosphorylation-dependent antibody, reacts only with NF-M transfected cells, whereas both NF-M and NF-H transfected cells are reactive with SMI 32 , the antibody against the nonphosphorylated neurofilament proteins. $C$, Immunoblotting of cytoskeletal material form cell line L929-S-H 15 separated by 2-dimensional NEPHGE-PAGE with SMI 32 demonstrated that the pI value of transfected NF-H (arrowhead) was approximately 7 . The basic end of the $\mathrm{pH}$ gradient is on the right. The positions of molecular-mass markers are indicated for both $A$ and $B$.

\section{4-}

49-

tionally, it was also observed that the immunofluorescent staining did not extend into the very center of this coil of filaments, suggesting the presence of a distinct structure or region around which the newly synthesized NF proteins are organized. After 48-72 hr filamentous NF-positive structures were the most prominent feature of the transfected cells, and the bright-staining juxtanuclear focus was no longer observed in most of the cells (Fig. 9B). This was in contrast with that observed with our NF-M transfections, in which the presence of the juxtanuclear focus persisted even into the later time points $(72 \mathrm{hr})$.

\section{Immunoelectron microscopic analysis of transfected cells}

$\mathrm{L} \mathrm{tk}^{-}$cells transiently transfected with pRSVi-NFH $2 \mathrm{~A}(+)$ were immunostained with mAb SMI 32 and rabbit anti-vimentin antibodies, followed by goat anti-mouse IgG secondary antibody labeled with $15-\mathrm{nm}$ colloidal gold and goat anti-rabbit IgG secondary antibody labeled with 5-nm colloidal gold. Expression of NF-H was detected on individual intermediate filaments that were also decorated with anti-vimentin antibody (Fig. 10 A$C)$. Comparable results were observed with one of the stably transfected NF-H cell lines (data not shown).

\section{Discussion}

We have successfully isolated and characterized a cDNA clone fully encoding for rat NF-H. To this date, no other fully encoding NF-H cDNA clone has been reported in the literature. Many of the deduced amino acid sequences for NF-H that became available during the course of this work were derived from partial cDNAs and genomic clones (Robinson et al., 1986; Breen et al., 1988; Dautigny et al., 1988; Julien et al., 1988; Lees et al., 1988; Mack et al., 1988; Schneidman et al., 1988; Lieberburg et al., 1989). Sequence analyses of the deduced NF-H polypeptide demonstrated that this protein conformed to the general tripartite structure exhibited by all IF proteins. The aminoterminal head domain showed the same conservation of size (length and mass), basic isoelectric point, and enrichment of 
serine residues as seen in the other type IV and type III IFs. The central rod domain was conserved with respect to size and positions of the $\alpha$-helical coiled-coils and their constituent heptad repeats. The only notable deviation from the consensus rod sequence was an insertion of 5 amino acid residues within rod linker region L2. This insertion probably does not drastically alter the helical rod domain's ability to form dimeric coiledcoils because the linker regions are flexible regions that are not involved in the hydrophobic interactions of the helical domains.

The long carboxyl-terminal tail domain of NF-H shares a feature common to all of the NF proteins, namely, the presence of glutamic acid-rich subregions that may partially contribute to the observed anomalous mobilities of the NFs in SDS-PAGE. However, the anomalous mobilities of NF-M and NF-H have been shown to be heavily influenced by the phosphorylation state of their tail domains: the more heavily phosphorylated the protein, the greater the reduction in mobility (Carden et al., 1985; Lewis and Nixon, 1988). The glutamic acid-rich region coincides with the region that has been implicated in binding silver when stained with the Bodian technique (Autilio-Gambetti et al., 1986).

Another common feature of the tail domains of NF-M and $\mathrm{NF}-\mathrm{H}$ is the occurrence of the tripeptide sequence KSP, which has been shown to be a neurofilament-specific phosphorylation site (Geisler et al., 1987; Lee et al., 1988). This tripeptide sequence occurs 5 times within rat NF-M (Napolitano et al., 1987) and 52 times in rat NF-H. The tripeptide repeats within all of the reported NF-H proteins are arranged in regular intervals, while the NF-M proteins generally do not have this property: human NF-M shows a periodic arrangement of direct sequence repeats that includes the KSP tripeptides (Myers et al., 1987). Interestingly, the regular spacing of the KSP repeats in rat and human NF-H places all of the serine residues, with only one exception, on the same side (cis) of the polypeptide chain. This cis-type positioning of these serine residues may play a role in their recognition by their putative NF-specific kinase(s) and may facilitate their subsequent phosphorylation. The KSP repeats in NF-M, even within the direct repeats of human NF-M, are not arranged in such a fashion and may explain differences in phosphorylation specificities observed in vitro.

The significance of the multiple phosphorylation sites on NF-M and NF-H is still unknown. Recent studies have put into doubt the possibility that phosphorylation of NF-H is important for the function of this protein to cross-bridge neurofilaments (Hisanaga and Hirokawa, 1989). However, it is likely that phosphorylation of NF-H mediates interactions between neurofilaments and other cellular elements. Studies from a number of laboratories have shown that phosphorylated epitopes of NF-H are predominant in the axons, whereas the nonphosphorylated epitopes are primarily in the neuronal cell bodies (Sternberger and Sternberger, 1983; Lee et al., 1986). Antibodies have been described that distinguish the phosphorylated and nonphosphorylated forms of NF-H and NF-M, and these antibodies distinguish KSP-containing epitopes on NF-H in phosphorylated and nonphosphorylated states (Lee et al., 1988). These antibodies will presumably not detect the presence of phosphorylation sites on neurofilaments other than the multiple KSP regions.

Using a number of different NF phosphorylation-state-sensitive antibodies, we found that $\mathrm{L} \mathrm{tk}^{-}$and $\mathrm{L} 929$ cells expressed the transfected NF-M protein in a phosphorylated form. Surprisingly, transfected NF-H does not appear to be phosphorylat-
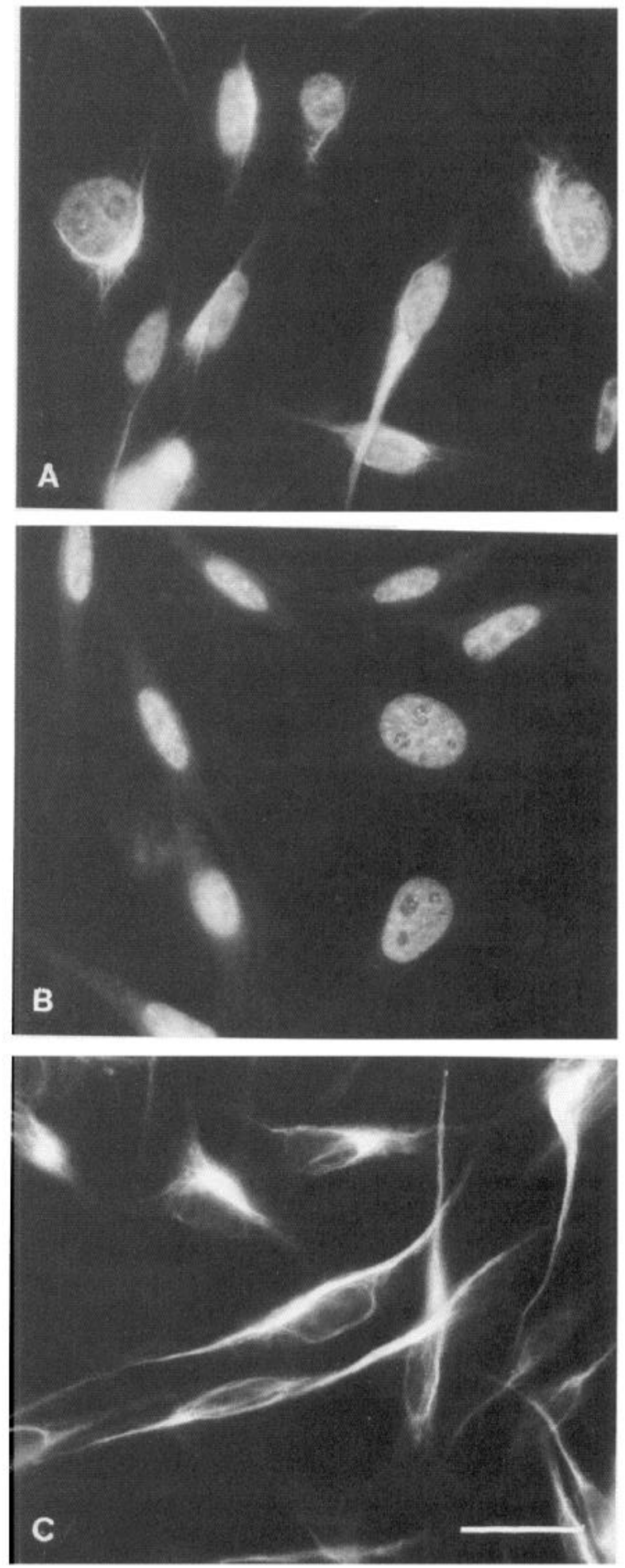

Figure 8. Alkaline phosphatate treatment of stable transfectant L-S-M 15-1. A, L-S-M 15-1 cells stained with the phosphorylation-dependent mAb SMI 31. B, L-S-M 15-1 cells treated with alkaline phosphatase, then stained with $\mathrm{mAb}$ SMI 31. $C$, Alkaline phosphatase-treated L-S-M 15-1 cells stained with the phosphorylation-independent mAb BMB NF160. Scale bar, $25 \mu \mathrm{m}$.

ed in these cells, even though there are approximately 10 times the number of potential phosphorylation sites on rat NF-H than on rat NF-M. The lack of phosphorylation of NF-H on the multiple KSP repeats in the transfected fibroblasts was shown not only by the absence of specific filamentous staining in the 

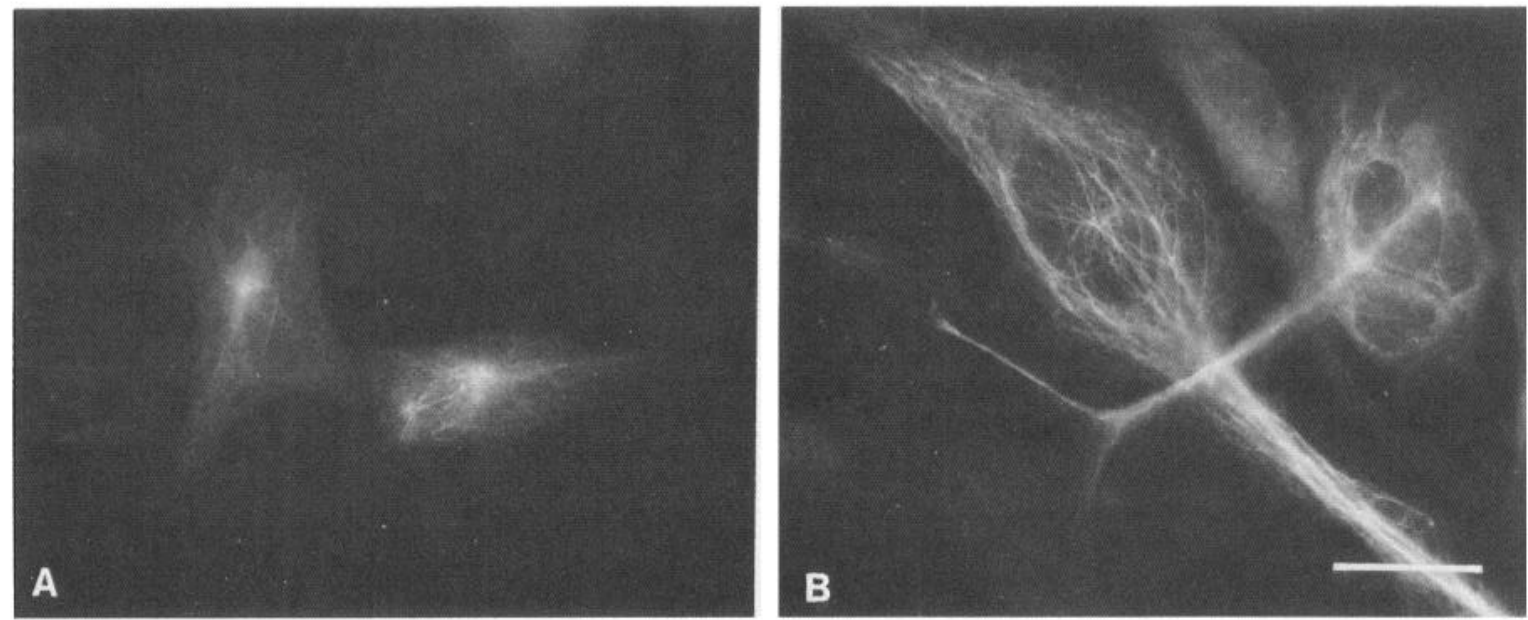

Figure 9. Time-course staining of $\mathrm{L}_{\text {tk }}^{-}$cells transiently transfected with NF expression constructs. $A$, Cells transfected with pRSVi-NFH $2 \mathrm{~A}(+)$, then stained with mAb SMI 32, $24 \mathrm{hr}$ after transfection. $B$, Cells from the same experiment as in $A$, except that the cells were stained $72 \mathrm{hr}$ after transfection. Scale bar, $25 \mu \mathrm{m}$.
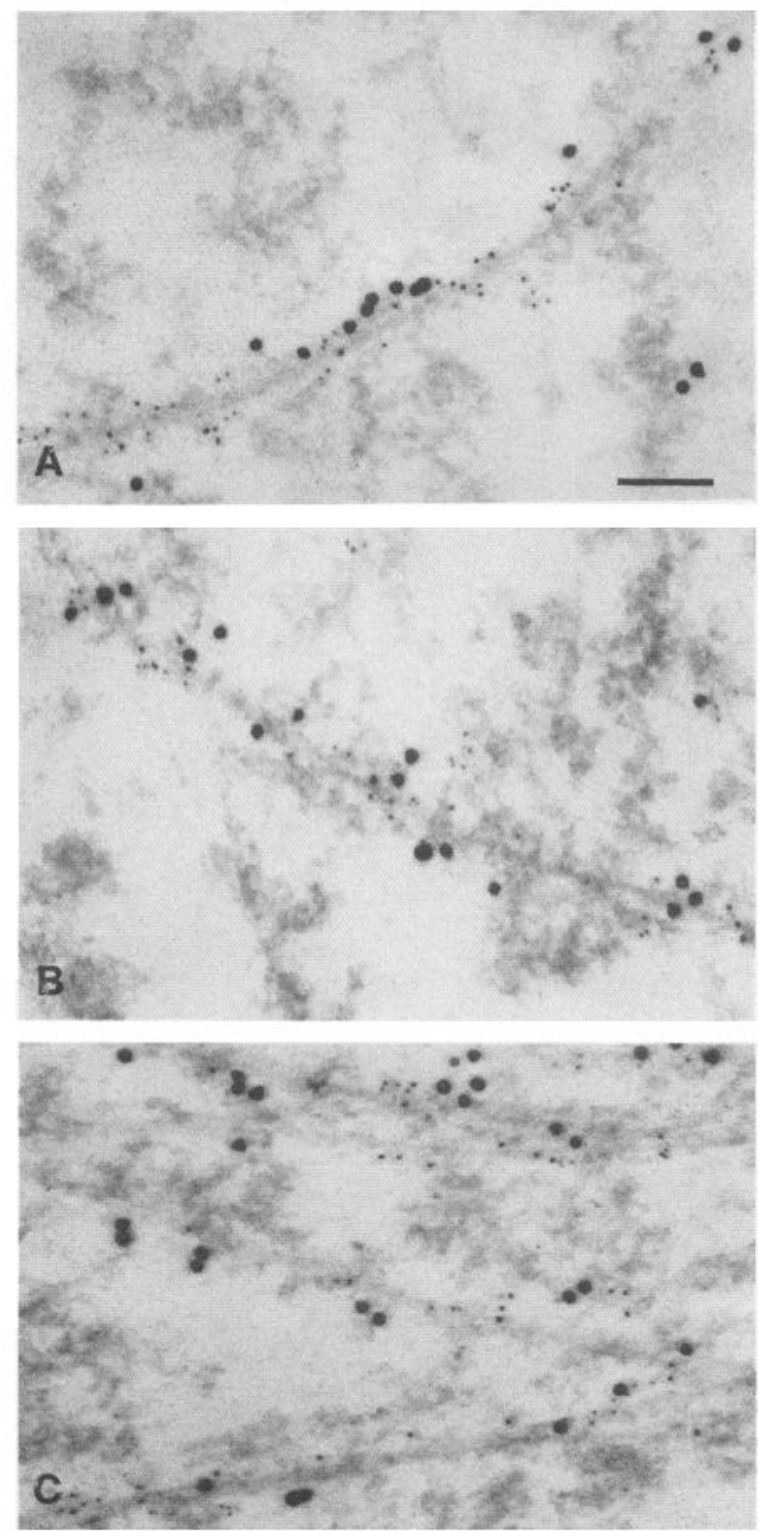

cells using antibodies to phosphorylated NF-H, but also by the mobility of the NF-H protein from transfected cells on both 1and 2-dimensional gels, which is consistent with a predominantly nonphosphorylated protein. NF-H protein from the transfected cells was recognized only by the antibody specific for nonphosphorylated NF-H by immunofluorescence staining, as well as by Western blots. These results suggest that NF-H cannot be readily phosphorylated by protein kinases present in fibroblasts, and that its phosphorylation may require a neurofilament-specific protein kinase, such as the one recently described by Wible et al. (1989). On the other hand, NF-M apparently can be phosphorylated by the kinases present in the fibroblasts. This result is consistent with in vitro experiments, where it has been shown that NF-M protein is easily phosphorylated by kinases such as CAMP-dependent protein kinases (Leterrier et al., 1981) and $\mathrm{Ca}^{2+} /$ calmodulin-dependent kinase (Vallano et al., 1985), which are not cell-type specific.

Our results demonstrate the ability of NF-M and NF-H proteins to form filamentous heteropolymers with endogenously expressed vimentin by colocalization at both the light and electron microscopic levels and by the collapse of both types of filaments into a juxtanuclear cap upon treatment with colchicine (S.S.M. Chin and R.K.H. Liem, unpublished observations). However, from these results, we do not know the nature of the protomeric subunits and how these are arranged to form higherordered structures. The basic protomeric subunit, at least for type III IFs, has been shown to be a dimer usually in the form of a homodimer with the protein chains aligned parallel and in register (Steinert and Roop, 1988). Heterodimers formed between different type III IF proteins have also been observed [e.g., vimentin and desmin (Quinlan and Franke, 1982), and vimentin and GFAP (Quinlan and Franke, 1983)]. These dimers

Figure 10. Immunoelectron localization of NF-H and vimentin in transiently transfected $\mathrm{L} \mathrm{tk}^{-}$cells. Triton X-100-extracted cytoskeletons were immunostained with $\mathrm{mAb}$ SMI 32 and rabbit anti-vimentin, then reacted with secondary antibodies that were labeled with colloidal gold particles. $A-C$, Individual IFs were clearly immunostained for both NF-H (15-nm gold particles) and vimentin (5-nm gold particles). Scale bar, $0.1 \mu \mathrm{m}$. 
appear to form tetramers, whose exact nature is still controversial, that are involved in the first stages of forming higherordered IF structures. In our system, it is important to first investigate the dimeric nature of the NF-vimentin heteropolymers in order to understand how these 2 proteins coassemble into filaments. The heteropolymers may be composed of NF dimers and vimentin dimers arranged into a filamentous superstructure or the heteropolymers may be composed of NFvimentin heterodimers as their basic structural subunit. Resolution of this question by chemical cross-linking experiments may also provide us with further insight on how the switch from vimentin to neurofilament expression is accommodated within developing neurons.

Establishment of NF-M- and NF-H-expressing stable cell lines was relatively easily accomplished and demonstrated that expression and polymerization of these 2 proteins do not adversely affect cell function. The successful assembly of these 2 proteins in the absence of the other triplet proteins also demonstrates that the NF proteins are unlike the keratins, which assemble only in the presence of an obligate keratin partner. This behavior is more akin to that of the type III IFs, which can form heteropolymers among themselves.

Finally, the results of the transfection experiments described in this paper extend observations of NF-H and NF-M phosphorylation into an in vivo system. The availability of unmodified NF-H protein through our stably transfected cell lines, especially the L929-derived cell lines, which express relatively large quantities of protein and grow well in suspension, has provided us with a convenient source of substrate for future identification and isolation of neurofilament-specific kinases.

\section{References}

Autilio-Bambetti L, Crane R, Gambetti P (1986) Binding of Bodian's silver and monoclonal antibodies to defined regions of human neurofilament subunits: Bodian's silver reacts with a highly charged unique domain of neurofilaments. J Neurochem 46:366-370.

Biggin MD, Gibson TJ, Hong GF (1983) Buffer gradient gels and [ $\left.{ }^{35} \mathrm{~S}\right]$ label as an aid to rapid DNA sequence determination. Proc Natl Acad Sci USA 80:3963-3965.

Blose SH (1981) The distribution of $10 \mathrm{~nm}$ filaments and microfilaments in endothelial cells during mitosis: double-label immunofluorescence study. Cell Motility 1:417-431.

Breen KC, Robinson PA, Wion D, Anderton BH (1988) Partial sequence of the rat heavy neurofilament polypeptide (NF-H): identification of putative phosphorylation sites. FEBS Lett 241:213-218.

Butler M, Shelanski ML (1986) Microheterogeneity of microtubuleassociated $\tau$ proteins is due to differences in phosphorylation. J Neurochem 47:1517-1522.

Carden MJ, Schlaepfer WW, Lee VM (1985) The structure, biochemical properties, and immunogenicity of neurofilament peripheral regions are determined by phosphorylation state. J Biol Chem 260:98059817.

Chamberlain JP (1979) Fluorographic detection of radioactivity in polyacrylamide gels with the water-soluble fluor, sodium salicylate. Anal Biochem 98:132-135.

Chin SSM, Liem RKH (1989) Expression of rat neurofilament proteins NF-L and NF-M in transfected non-neuronal cells. Eur $\mathbf{J}$ Cell Biol $50: 475-490$.

Chirgwin JM, Przybyla AE, MacDonald RJ, Rutter WJ (1979) Isolation of biologically active ribonucleic acid from sources enriched in ribonuclease. Biochemistry 18:5294-5299.

Dale RMK, McClure BA, Houchins JP (1985) A rapid single-stranded cloning strategy for producing a sequential series of overlapping clones for use in DNA sequencing: application to sequencing the corn mitochondrial 18S rDNA. Plasmid 13:31-40.

Dautigny A, Pham-Dinh D, Roussel C, Felix JM, Nussbaum JL, Jolles $P(1988)$ The large neurofilament subunit $(\mathrm{NF}-\mathrm{H})$ of the rat: cDNA cloning and in situ detection. Biochem Biophys Res Comm 154:10991106.

Davis LG, Dibner MD, Battey JF (1986) Basic methods in molecular biology. New York: Elsevier.

Forman BM, Yang C, Stanley F, Casanova J, Samuels HH (1988) c-erbA protooncogenes mediate thyroid hormone-dependent and independent regulation of the rat growth hormone and prolactin genes. Mol Endocrinol 2:902-911.

Gardner EE, Dahl D, Bignami A (1984) Formation of $10 \mathrm{~nm}$ filaments from the 150 -k-dalton neurofilament protein in vitro. J Neurosci Res 11:145-155.

Geisler N, Weber K (1981) In vitro self-assembly of the 68,000 molecular weight component of the mammalian neurofilament triplet proteins into intermediate-size filaments. J Mol Biol 151:565-571.

Geisler N, Kaufmann E, Fischer S, Plessmann U, Weber K (1983) Neurofilament architecture combines structural principles of intermediate filaments with carboxy-terminal extensions increasing in size between triplet proteins. EMBO J 2:1295-1302.

Geisler N, Vandekerckhove J, Weber K (1987) Location and sequence characterization of the major phosphorylation sites of the high molecular mass proteins $M$ and H. FEBS Lett 221:403-407.

Graham FL, van der Eb AJ (1973) A new technique for the assay of infectivity of human adenovirus 5 DNA. Virology 52:456-467.

Hirokawa N, Glicksman MA, Willard MB (1984) Organization of mammalian neurofilament polypeptides within the neuronal cytoskeleton. J Cell Biol 98:1523-1536.

Hisanaga S, Hirokawa N (1989) The effects of dephosphorylation on the structure of the projections of neurofilament. J Neurosci 9:959966.

Julien J-P, Cote F, Beaudet L, Sidky M, Flavell D, Grosveld F, Mushynski W (1988) Sequence and structure of the mouse gene coding for the largest neurofilament subunit. Gene 68:307-314.

Kaufmann E, Geisler N, Weber K (1984) SDS-PAGE strongly overestimates the molecular masses of the neurofilament proteins. FEBS Lett 170:81-84.

Lacmmli UK (1970) Cleavage of structural proteins during the assembly of the head of bacteriophage T4. Nature 227:680-685.

Laskey RA, Mills AD (1975) Quantitative film detection of ${ }^{3} \mathrm{H}$ and ${ }^{14} \mathrm{C}$ in polyacrylamide gels by fluorography. Eur J Biochem $56: 335-$ 341.

Lee VM-Y, Carden MJ, Trojanowski JQ (1986) Novel monoclonal antibodies provide evidence for the in situ existence of a nonphosphorylated form of the largest neurofilament subunit. J Neurosci 6: 850-858.

Lee VM-Y, Otvos L, Carden MJ, Hollosi M, Dietzschold B, Lazzarini RA (1988) Identification of the major multiphosphorylation site in mammalian neurofilaments. Proc Natl Acad Sci USA 85:1998-2002.

Lees JF, Shneidman PS, Skuntz SF, Carden MJ, Lazzarini RA (1988) The structure and organization of the human heavy neurofilament subunit (NF-H) and the genc cncoding it. EMBO J 7:1947-1955.

Leterrier JF, Liem RKH, Shelanski ML (1981) Preferential phosphorylation of the 150,000 molecular weight component of neurofilaments by a cyclic AMP-dependent, microtubule-associated protein kinase. J Cell Biol 90:755-760.

Lewis SE, Nixon RA (1988) Multiple phosphorylated variants of the high molecular mass subunit of neurofilaments in axons of retinal cell neurons: characterization and evidence for their differential association with stationary and moving neurofilaments. J Cell Biol 107:26892701.

Lieberburg I, Spinner N, Snyder S, Anderson J, Goldgaber D, Smulowtiz M, Carroll Z, Emanuel B, Breitner J, Rubin L (1989) Cloning of a cDNA encoding the rat high molecular weight neurofilament peptide (NF-H): developmental and tissue expression in the rat, and mapping of its human homologuc to chromosome 1 and 22. Proc Natl Acad Sci USA 86:2463-2467.

Liem RKH, Hutchison SB (1982) Purification of individual components of the neurofilament triplet: filament assembly from the $70000-$ dalton subunit. Biochemistry 21:3221-3226.

Liem RKH, Yen SH, Salomon GD, Shelanski ML (1978) Intermediate filaments in nervous tissues. J Cell Biol 79:637-645.

Liem RKH, Chin SSM, Moraru E, Wang E (1985) Monoclonal antibodies to epitopes on different regions of the 200,000 dalton neurofilament protein. Probes for the geometry of the filament. Exp Cell Res 156:419-428.

Lopata MA, Cleveland DW, Sollner-Webb B (1984) High level tran- 
sient expression of a chloramphenicol acetyltransferase gene by DEAEdextran mediated DNA transfection coupled with a dimethylsulfoxide or glycerol shock treatment. Nucleic Acids Res 12:5707-5717.

Mack K, Currie JR, Soifer D (1988) cDNA coding for the tail region of the high molecular weight rabbit neurofilament protein NF-H. J Neurosci Res 20:129-136.

Melton DA, Krieg PA, Rebaghati M, Maniatis T, Zinn K, Green MR (1984) Etficient in vitro synthesis of biologically active RNA and RNA hybridization probes from plasmids containing a bacteriophage SP6 promoter. Nucleic Acids Res 12:7035-7056.

Monteiro MJ, Cleveland DW (1989) Expression of NF-L and NF-M in fibroblasts reveals coassembly of neurofilaments and vimentin subunits. J Cell Biol 108:579-593.

Myers MW, Lazzarini RA, Lee VM-Y, Schlaepfer WW, Nelson DL (1987) The human mid-size neurofilament subunit: a repeated protein sequence and the relationship of its gene to the intermediate filament gene family. EMBO J 6:1617-1626.

Napolitano EW, Chin SSM, Colman DR, Liem RKH (1987) Complete amino acid sequence and in vitro expression of rat NF-M, the middle molecular weight neurofilament protein. J Neurosci 7:2590-2599.

Oblinger MM (1987) Characterizaiton of posttranslational processing of the mammalian high-molecular-weight neurofilament protein in vivo. J Neurosci 7:2510-2521.

O'Farrell PH (1975) High resolution two-dimensional electrophoresis of proteins. J Biol Chem 250:4007-4021.

Parker BA, Stark GR (1979) Regulation of simian virus 40 transcription: sensitive analysis of the RNA species present early in infections by virus or viral DNA. Virology 31:360-369.

Pustell J, Kafatos FC (1984) A convenient and adaptable package of computer programs for DNA and protein sequence management, analysis, and homology determination. Nucleic Acids Res 12:643655.

Quinlan RA, Franke WW (1982) Heteropolymer filaments of vimentin and desmin in vascular smooth muscle tissue and cultured baby hamster kidney cells demonstrated by chemical crosslinking. Proc Natl Acad Sci USA 79:3452-3546.

Quinlan RA, Franke WW (1983) Molecular interactions in intermediate-sized filaments revealed by chemical cross-linking: heteropolymers of vimentin and glial filament protein in cultured human glioma cells. Eur J Biochem 132:477-484.
Reynolds ES (1963) The use of lead citrate at high pH as an electronopaque stain in electron microscopy. J Cell Biol 17:208-212.

Rigby PWJ, Dieckman M, Rhodes C, Berg P (1977) Labeling deoxyribonucleic acid to high specific activity in vitro by nick translation with DNA polymerase I. J Mol Biol 113:237-251.

Robinson PA, Wion D, Anderton BH (1986) Isolation of a cDNA for the rat heavy neurofilament polypeptide (NF-H). FEBS Lett 209:203205.

Rodriguez J, Deinhardt F (1960) Preparation of a semipermanent mounting medium for fluorescent antibody studies. Virology 12:316317.

Sanger FA, Coulsen AR, Barrel BG, Smith JH, Roe B (1980) Cloning in single-stranded hacteriophage as an aid to rapid DNA sequencing. J Mol Biol 143:161-178.

Schneidman PS, Carden MJ, Lees JF, Lazzarini RA (1988) The structure of the largest murine neurofilament protein (NF-H) as revealed by cDNA and genomic sequences. Mol Brain Res 4:217-231.

Steinert PM, Roop DR (1988) Molecular and cellular biology of intermediate filaments. Annu Rev Biochem 57:593-625.

Sternberger LA, Sternberger NH (1983) Monoclonal antibodies distinguish phosphorylated and nonphosphorylated forms of neurofilaments in situ. Proc Natl Acad Sci USA 80:6126-6130.

Towbin H, Straelin T, Gordon J (1979) Electrophoretic transfer of proteins from polyacrylamide gels to nitrocellulose: procedure and some application. Proc Natl Acad Sci USA 76:4350-4354.

Vallano ML, Buckholz TM, DeLorenzo RJ (1985) Phosphorylation of neurofilament proteins by endogenous calcium/calmodulin-dependent protein kinase. Biochem Biophys Res Commun 130:957-963.

Vogelstein B, Gillespie D (1979) Preparative and analytical purification of DNA from agarose. Proc Natl Acad Sci USA 76:615-619.

Wible BA, Smith KE, Angelides KJ (1989) Resolution and purification of a neurofilament-specific kinase. Proc Natl Acad Sci USA 86:720 724

Willard MB, Simon C (1981) Antibody decoration of neurofilaments. J Cell Biol 89:198-205.

Wood JN, Lathangue NB, McLachlan DR, Smith BJ, Anderton BH, Dowding AJ (1985) Chromatin proteins share antigenic determinants with neurofilaments. J Neurochem 44:149-154. 